\title{
Directional Solidification of AISi7Fe1 Alloy Under Forced Flow Conditions: Effect of Intermetallic Phase Precipitation and Dendrite Coarsening
}

\author{
HAIJIE ZHANG, MENGHUAI WU, CHRISTIAN M.G. RODRIGUES, \\ ANDREAS LUDWIG, and ABDELLAH KHARICHA
}

\begin{abstract}
A forced flow was experimentally shown to influence the solidification microstructure of metal alloys by modifying the coarsening/ripening law. In some technical alloys (AlSi7Fe1), this flow effect can also be significantly suppressed due to the formation of intermetallic precipitates $\left(\beta-\mathrm{Al}_{5} \mathrm{FeSi}\right)$ that can block the flow in the mushy region. The forced flow was induced by a rotating magnetic field (RMF). Herein, a three-phase volume-average-based solidification model is introduced to reproduce the above experiment. The three phases are the melt, the primary solid phase of columnar dendrites, and the second solid phase of intermetallic precipitates. The dynamic precipitation of the intermetallic phase is modelled, and its blocking effect on the flow is considered by a modified permeability. Dendrite coarsening, which influences the permeability, is also considered. The RMF induces a strong azimuthal flow and a relatively weak meridional flow (Ekman effect) at the front of the mushy zone during unidirectional solidification. This forced flow reduces the mushy zone thickness, induces the central segregation channel, affects the distribution of the intermetallic precipitates, and influences dendrite coarsening, which in turn modifies the interdendritic flow. Both interdendritic flow and the microstructure formation are strongly coupled. The modelling results support the explanation of Steinbach and Ratke - the formed intermetallic precipitates $\left(\beta-\mathrm{Al}_{5} \mathrm{FeSi}\right)$ can block the interdendritic flow, and hence influence the coarsening law. The distribution of $\beta-\mathrm{Al}_{5} \mathrm{FeSi}$ is dominantly influenced by the flow-induced macrosegregation. The simulation results of the $\mathrm{Si}$ and $\mathrm{Fe}$ distribution across the sample section are compared with the experimental results, showing good simulation-experiment agreement.
\end{abstract}

HAIJIE ZHANG, MENGHUAI WU, CHRISTIAN M.G. RODRIGUES, ANDREAS LUDWIG, and ABDELLAH KHARICHA are with the Chair for Simulation and Modeling of Metallurgy Processes, Department of Metallurgy, University of Leoben, Franz-Jose-Str. 18, 8700 Leoben, Austria. Contact e-mail: menghuai.wu@unileoben.ac.at.

Manuscript submitted January 18, 2021; accepted April 14, 2021.

Article published online May 10, 2021 
During alloy solidifications the flow can influence the mushy zone by inducing macrosegregation, modifying the solidification microstructure, and influencing the formation of intermetallic precipitates. The resulting microstructural features can in turn affect the melt flow by changing the flow intensity and flow pattern. A three-phase volume-average-based solidification model is introduced to study the flow-solidification interaction, and hence to improve the knowledge on the formation mechanism of intermetallics and their effect on solidification. (a) Schematic for the flow pattern and formation of different phases; (b) experiment-simulation comparison of macrosegregation $(\mathrm{Fe})$ across the diameter of as-solidified sample.

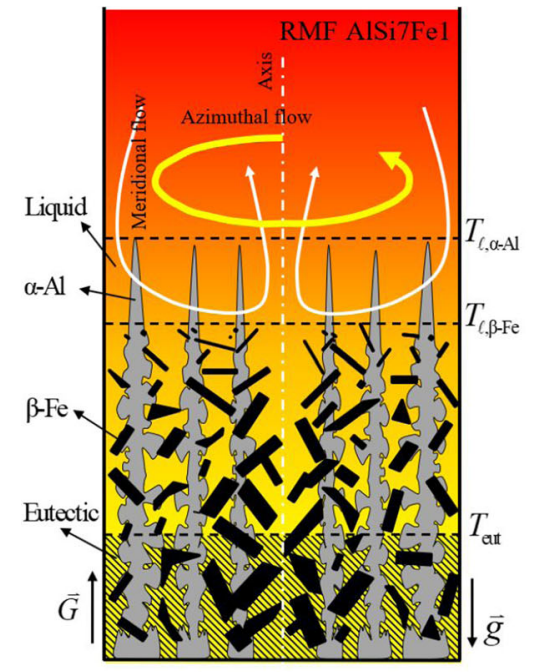

(a)

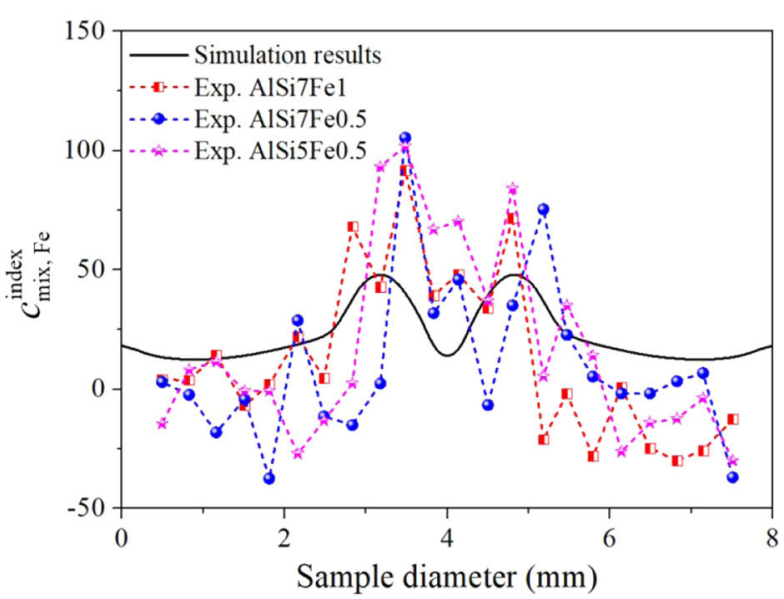

(b)

https://doi.org/10.1007/s11661-021-06295-5

(C) The Author(s) 2021

\section{INTRODUCTION}

MELT flow is a natural phenomenon that occurs during the alloy solidification of almost all casting processes. The flow can influence the mushy zone by inducing macrosegregation, ${ }^{[1]}$ modifying the solidification microstructure, ${ }^{[2]}$ causing fragmentation, ${ }^{[3]}$ and even influencing the formation of precipitates. ${ }^{[4]}$ The resulting microstructural features in the mushy zone can in turn affect the fluid flow by changing the flow intensity and flow pattern. ${ }^{[5]} \mathrm{A}$ recent experimental study has demonstrated the importance of the above flow-solidification interaction in the formation of the microstructure, i.e., the flow can adapt the coarsening law. ${ }^{[2,6]}$ Classically, the coarsening law is described by the correlation between the secondary dendrite arm spacing $\left(\lambda_{2}\right)$ and the local solidification time $\left(t_{\mathrm{f}}\right)^{[7,8]}$.

$$
\lambda_{2}=A\left(M \cdot t_{\mathrm{f}}\right)^{b},
$$

where $A$ is a geometric magnification factor, $M$ is the alloy-dependent magnification factor, and $b$ is the ripening exponent. Under pure diffusive conditions (or when the flow is negligible), $b$ should be $1 / 3$. Unidirectional solidification experiments on the alloy AlSi7 showed that the ripening exponent $(b)$ increased to $1 / 2$ when a forced flow was imposed by applying a rotating magnetic field (RMF). ${ }^{[2,6]}$ Interestingly, the same experiments were repeated with another alloy $(\mathrm{AlSi} 7 \mathrm{Fe} 1)$ in which intermetallic precipitates formed $\left(\beta-\mathrm{Al}_{5} \mathrm{FeSi}\right)$ during solidification, and the results showed that the applied RMF seemed to have no influence on the coarsening/ripening law, i.e., $b$ was maintained at $1 / 3$. A tentative explanation for the undisturbed $\lambda_{2}-t_{\mathrm{f}}$ relationship in the solidification of AlSi7Fel under RMF is that the formation of the intermetallic precipitates $\left(\beta-\mathrm{Al}_{5} \mathrm{FeSi}\right)$ suppresses the interdendritic flow, so that the conditions of solidification and the corresponding coarsening/ripening phenomenon approaches the pure diffusive case. ${ }^{[6,9]}$

The motivation of the current work is to use a modelling approach to reproduce the above experiments, focusing on the blocking effect of intermetallic precipitates on the flow and its further impact on the microstructure formation. The influence of $\beta-\mathrm{Al}_{5} \mathrm{FeSi}$ on the flow permeability in the interdendritic mushy region was analysed by Puncreobutr et al. ${ }^{[10]}$ for the alloy $\mathrm{Al}-7.52 \mathrm{Si}-3.53 \mathrm{Cu}-0.59 \mathrm{Fe}$. A $4 \mathrm{D}$ in situ synchrotron $\mathrm{X}$-ray tomography technique was used to reconstruct the microstructure including the primary aluminium dendrites and precipitates during solidification (Figure 1(a)), which was further used to perform computational fluid dynamics (CFD) calculations to estimate the permeability (Figure 1(b)). The results 


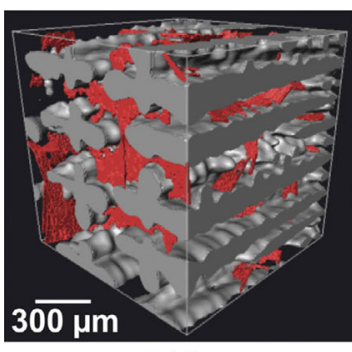

(a)

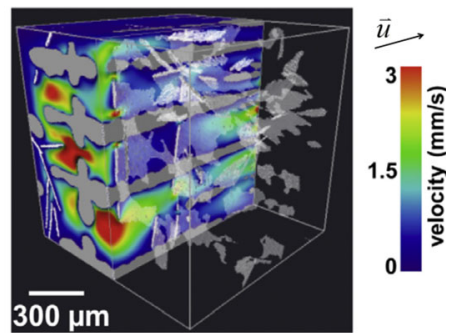

(b)
Fig. 1-CFD study of the effect of intermetallic precipitates on the interdendritic flow. (a) Reconstruction of the primary aluminium dendrites (grey) and intermetallic precipitates (red) and (b) liquid velocity at solid fraction of $0.33\left(848 \mathrm{~K}\left(575^{\circ} \mathrm{C}\right)\right)$. Reprinted from reference, ${ }^{[10]}$ under the terms of the Creative Commons CC BY license.

demonstrated the blocking effect of the intermetallic phase on the fluid flow, particularly in the direction parallel to the primary dendrites.

In most numerical models $\lambda_{2}$ was usually assumed to be a constant value for calculating the mushy permeability, and it was taken from the as-solidified structure. $^{[5,11]}$ This assumption may reduce the credibility of the numerical model, as $\lambda_{2}$ is known to change with time due to coarsening/ripening. Recently, a general coarsening equation that accounts for the effects of growth, curvature-driven coarsening, and interface coalescence was proposed by Neumann-Heyme et $a l .{ }^{[12]}$ The interfacial area density $\left(S_{\mathrm{v}}\right)$ was described as a function of the local liquid volume fraction and time. The growth and coarsening of dendrites can then be considered via a time-dependent $\lambda_{2}$ that is expressed by a $\lambda_{2}-S_{\mathrm{v}}$ relation, suggested by $\mathrm{Li}$ and Beckermann, ${ }^{[13]}$ into the interfacial area density equation of Neumann-Heyme et al. ${ }^{[12]}$ This makes it possible to consider the effect of dendrite coarsening on the flow.

In the current study, a three-phase volume-average-based solidification model ${ }^{[14,15]}$ is modified to simulate the solidification of an AlSi7Fel alloy. The three phases are the melt, the primary solid phase of columnar dendrites, and the second solid phase of intermetallic precipitates. The growth/coarsening of the dendrites of the primary phase is considered, and the formation/growth of the intermetallic precipitates is also modelled. The block effect of the intermetallic precipitates on the flow is considered through the $f_{\beta}$-dependent permeability. The main goal is to quantify the effect of the intermetallic phase and dendrite coarsening on the solidification of AlSi7Fe alloy under RMF, and hence to explain the experimental results of Steinbach et al. ${ }^{[6]}$ i.e., the experimental observation of $b=1 / 3$ (coarsening/ripening law exponent) in the presence of RMF when sufficient intermetallic precipitates are present. Although the solidification of AlSi7Fel alloy was also numerically studied by Budenkova et al. ${ }^{[16]}$ the blocking effect of the precipitates and the dendrite coarsening were ignored.

\section{MODEL DESCRIPTION}

A multiphase volume-average-based solidification model was previously developed by $\mathrm{Wu}$ et al..$^{[15,17]}$ Herein, this volume-average-based solidification model is modified to consider the formation of intermetallic precipitates $\left(\beta-\mathrm{Al}_{5} \mathrm{FeSi}\right)$. Three phases are consideredthe liquid melt, the columnar dendrites as the first solid phase, and the intermetallic precipitates as the second solid phase. The columnar dendrites are simplified as cylinders growing unidirectionally along the temperature gradient, and their tips are traced according to the Lipton-Glicksman-Kurz (LGK) model. ${ }^{[18]}$ The intermetallic phase $\left(\beta-\mathrm{Al}_{5} \mathrm{FeSi}\right.$ precipitates) forms during the binary eutectic solidification. A thermodynamic equilibrium is presumed at the solid-liquid interface. The concentration differences between the thermodynamic equilibrium concentration of the liquid melt at the solid-liquid interface and the volume-averaged liquid concentration serve as the driving force for the growth of columnar dendrites and intermetallic precipitates. The resistance of the mushy zone (columnar dendrites and precipitates) to the fluid flow is calculated using a modified permeability model. ${ }^{[10]}$ The primary dendrite arm spacing is taken from previous experiments, ${ }^{[6,9]}$ while the secondary dendrite arm spacing follows the ripening law. ${ }^{[12]}$ The most important model features are described below.

\section{A. Phase Definition and Corresponding Mass Transfer Rate}

The solidification of the AlSi7Fe1 alloy starts with the development of primary aluminium dendrites, followed by the formation of $\beta-\mathrm{Al}_{5} \mathrm{FeSi}$ during the binary eutectic reaction, and ends with the ternary eutectic reaction at $850 \mathrm{~K}$. Previous experiments ${ }^{[6,9]}$ did not provide evidence of equiaxed crystals in the sample. Therefore, we ignore the equiaxed phase in the current model. The three phases (the liquid melt, the columnar dendrites, and the intermetallic $\beta-\mathrm{Al}_{5} \mathrm{FeSi}$ precipitates) are quantified by their volume fractions $-f_{\ell}, f_{\mathrm{c}}$, and $f_{\beta}$. The solidification of the columnar trunks and the formation of intermetallic precipitates are modelled differently. The small part of $\alpha$-Al phase which forms during the binary and ternary eutectic reactions is considered a further growth of the primary columnar trunks. The columnar trunks are assumed to be rigid and stationary, and the formed $\beta-\mathrm{Al}_{5} \mathrm{FeSi}$ is assumed to be immediately captured by columnar dendrites, making them also rigid/stationary. ${ }^{[19,20]}$ According to the latest work published by Puncreobutr et al., ${ }^{[21]}$ nucleation of $\beta-\mathrm{Al}_{5} \mathrm{FeSi}$ is presumed to occur instantaneously on/near the primary aluminium dendrites once the thermal conditions from a phase diagram are met. The solidification shrinkage is ignored in this study, and the thermo-solutal convection is modelled using the Boussinesq approach. It is known that the intermetallic phase is denser than the columnar dendrites $\left(\rho_{\beta}>\rho_{\mathrm{c}}\right)$. As the $\beta-\mathrm{Al}_{5} \mathrm{FeSi}$ is captured by the columnar dendrites, the buoyancy force on the $\beta-\mathrm{Al}_{5} \mathrm{FeSi}$ plays no role on the 
phase sedimentation, hence $\rho_{\beta}$ can also be treated equal to $\rho_{\mathrm{c}}$. The mass conservation equations are

$$
\begin{aligned}
\frac{\partial}{\partial t}\left(f_{\ell} \rho_{\ell}\right)+\nabla \cdot\left(f_{\ell} \rho_{\ell} \vec{u}_{\ell}\right) & =-M_{\ell \mathrm{c}}-M_{\ell \beta}, \\
\frac{\partial}{\partial t}\left(f_{\mathrm{c}} \rho_{\mathrm{c}}\right) & =M_{\ell \mathrm{c}}, \\
\frac{\partial}{\partial t}\left(f_{\beta} \rho_{\beta}\right) & =M_{\ell \beta},
\end{aligned}
$$

where $M_{\ell c}$ is the mass transfer rate from the liquid melt to the columnar dendrites due to the solidification of the primary aluminium, $M_{\ell \beta}$ is the mass transfer rate from the liquid melt to $\beta-\mathrm{Al}_{5} \mathrm{FeSi}$ due to the formation of intermetallic precipitates, $\vec{u}_{\ell}$ is the velocity of the melt, and $\rho_{\ell}, \rho_{\beta}, \rho_{\mathrm{c}}$ are the densities of the different phases.

The net mass transfer rates from the liquid melt to either of the solid phases $\left(M_{\ell c}\right.$ and $\left.M_{\ell \beta}\right)$ are governed by the solute diffusion in the interdendritic melt. The concentration difference between the liquid thermodynamic equilibrium concentrations $\left(c_{\ell, \mathrm{Si}}^{*}, c_{\ell, \mathrm{Fe}}^{*}\right)$ at the solid-liquid interface and the volume-averaged concentrations $\left(c_{\ell, \mathrm{Si}}, c_{\ell, \mathrm{Fe}}\right)$ in the interdendritic liquid act as the driving forces for the transfer. The columnar trunks are assumed to be cylinders, and their tip fronts are traced using the LGK model. ${ }^{[18]}$ The growth of the columnar phase $\left(M_{\ell c}\right)$ is assumed to be governed only by the diffusion of $\mathrm{Si}$ in the melt:

$$
\begin{gathered}
M_{\ell \mathrm{c}}=2 v_{R_{\mathrm{c}}} \cdot \frac{R_{\mathrm{c}} \cdot \pi}{\lambda_{1}^{2}} \cdot \rho_{\mathrm{c}} \cdot f_{\ell}, \\
v_{R_{\mathrm{c}}}=\frac{D_{\ell, \mathrm{Si}}}{R_{\mathrm{c}}} \cdot \frac{\left(c_{\ell, \mathrm{Si}}^{*}-c_{\ell, \mathrm{Si}}\right)}{c_{\ell, \mathrm{Si}}^{*}\left(1-k_{\mathrm{Si}}\right)} \cdot \ln ^{-1}\left(\frac{R_{\mathrm{f}, \mathrm{c}}}{R_{\mathrm{c}}}\right),
\end{gathered}
$$

where $R_{\mathrm{c}}$ is the radius of the columnar trunk, $v_{R_{\mathrm{c}}}$ is the radial growth velocity, $\lambda_{1}$ is the primary dendrite arm spacing, $R_{\mathrm{f}, \mathrm{c}}$ is the limit of the radius of the columnar trunk, and $k_{\mathrm{Si}}$ is the solute partition coefficient of Si.

Based on the Al-Si-Fe ternary phase diagram, ${ }^{[22]}$ the solidification of AlSi7Fel starts with the primary aluminium while the $\mathrm{Fe}$ and $\mathrm{Si}$ elements are rejected into the liquid. It is followed by the binary eutectic, where $\beta-\mathrm{Al}_{5} \mathrm{FeSi}$ forms as precipitates. The enriched $\mathrm{Fe}$ in the interdendritic melt during the primary aluminium solidification is consumed/absorbed by the precipitation of $\beta-\mathrm{Al}_{5} \mathrm{FeSi}$. The Al-rich corner of the $\mathrm{Al}-\mathrm{Si}-\mathrm{Fe}$ ternary phase diagram is linearised. The liquidus surface can be expressed as

$$
T=T_{\mathrm{f}}+m_{\ell, \mathrm{Si}} c_{\ell, \mathrm{Si}}^{*}+m_{\ell, \mathrm{Fe}} c_{\ell, \mathrm{Fe}}^{*},
$$

where $m_{\ell, \mathrm{Si}}$ and $m_{\ell, \mathrm{Fe}}$ are the partial slopes of the liquidus surface with respect to the corresponding solute elements; $c_{\ell, \mathrm{Si}}^{*}$ and $c_{\ell, \mathrm{Fe}}^{*}$ are the equilibrium liquid concentration of $\mathrm{Si}$ and $\mathrm{Fe}$; and $T_{\mathrm{f}}$ is the melting point of pure Al. The solute concentrations $\left(c_{\mathrm{eut}, \mathrm{Si}}^{*}\right.$ and $\left.c_{\mathrm{eut}, \mathrm{Fe}}^{*}\right)$ along the binary eutectic valley are simplified as linear functions of $T$ :

$$
\begin{gathered}
c_{\mathrm{eut}, \mathrm{Si}}^{*}=131.020-0.139 \cdot T, \\
c_{\mathrm{eut}, \mathrm{Fe}}^{*}=-21.70691+0.02617 \cdot T .
\end{gathered}
$$

The formation of the $\beta-\mathrm{Al}_{5} \mathrm{FeSi}$ precipitates, represented by $M_{\ell \beta}$, is calculated by introducing a growth constant $g_{\beta}\left[{ }^{[23]}\right.$ :

$$
M_{\ell \beta}=g_{\beta} \cdot\left(c_{l, \mathrm{Fe}}-c_{l, \mathrm{Fe}}^{*}\right) \cdot \rho_{\beta} \cdot f_{\ell} .
$$

All unknown factors contributing to $M_{\ell \beta}$ such as the diffusion of $\mathrm{Fe}$ and $\mathrm{Si}$ around the precipitates and the effect of morphology are included in $g_{\beta}$. It is determined through a numerical parameter study (later section).

A value of 0.1 for $g_{\beta}$ is recommended for the current alloy and solidification conditions. The solidification path and the corresponding phase evolution under pure diffusive conditions are also analysed and evaluated against the results obtained using the commercial software Thermo-Calc and the inbuilt equilibrium solidification model.

\section{B. Blocking Effect of Intermetallic Precipitates}

The fluid flow in the mushy zone is approximated with Darcy's law in which its permeability is treated as a function of $\lambda_{1}$ and $\lambda_{2}$ by referring to the Carman-Kozeny approach. As aforementioned, the precipitated $\beta-\mathrm{Al}_{5} \mathrm{FeSi}$ is assumed to be immediately captured by the columnar dendrites. An extra resistance force in addition to the drag force by the columnar dendrites will be imposed on the liquid phase. Following Puncreobutr et al. ${ }^{[10]}$ the blocking effect of $\beta-\mathrm{Al}_{5} \mathrm{FeSi}$ on fluid flow in the mushy zone is treated by considering an additional coefficient $\left(1-\beta f_{\beta}\right)$ in the permeability:

$$
\begin{gathered}
K_{\mathrm{P}, \text { int }}=\left(1-\beta_{\mathrm{P}} f_{\beta}\right) K_{\mathrm{P}}, \\
K_{\mathrm{N}, \text { int }}=\left(1-\beta_{\mathrm{N}} f_{\beta}\right) K_{\mathrm{N}},
\end{gathered}
$$

where $K_{\mathrm{P}, \text { int }}$ and $K_{\mathrm{N} \text {,int }}$ are the permeability components of the flow parallel $(\mathrm{P})$ and normal $(\mathrm{N})$ to the primary dendrites in the presence of $\beta-\mathrm{Al}_{5} \mathrm{FeSi}$; and $K_{\mathrm{P}}, K_{\mathrm{N}}$ are the corresponding permeability components in the absence of $\beta-\mathrm{Al}_{5} \mathrm{FeSi}$. The values of the constants $\beta_{\mathrm{P}}$ and $\beta_{\mathrm{N}}$ are 15 and 10 , respectively. ${ }^{[10]} K_{\mathrm{P}}$ and $K_{\mathrm{N}}$, valid for the whole range of the liquid volume fraction, can be calculated according to Schneider and Beckermann $^{[24]}$.

$$
K_{\mathrm{P}}=\left\{\begin{array}{l}
{\left[4.53 \times 10^{-4}+4.02 \times 10^{-6}\left(f_{\ell}+0.1\right)^{-5}\right] \frac{\lambda_{1}^{2} f_{\ell}^{3}}{\left(1-f_{\ell}\right)} \quad\left(f_{\ell}<0.7\right)} \\
0.07425 \lambda_{1}^{2}\left[-\ln \left(1-f_{\ell}\right)-1.487+2\left(1-f_{\ell}\right)-0.5\left(1-f_{\ell}\right)^{2}\right] \quad\left(f_{\ell} \geq 0.7\right)
\end{array},\right.
$$




$$
K_{\mathrm{N}}=\left\{\begin{array}{l}
{\left[1.73 \times 10^{-3}\left(\frac{\lambda_{1}}{\lambda_{2}}\right)^{1.09}\right] \frac{\lambda_{2}^{2} f_{\ell}^{\beta}}{\left(1-f_{\ell}\right)^{0.749}} \quad\left(f_{\ell}<0.7\right)} \\
0.03979 \lambda_{1}^{2}\left[\begin{array}{rr}
-\ln \left(1-f_{\ell}\right)-1.476+2\left(1-f_{\ell}\right)-1.774\left(1-f_{\ell}\right)^{2} \\
+4.076\left(1-f_{\ell}\right)^{3}
\end{array}\right] \quad\left(f_{\ell} \geq 0.7\right)
\end{array} .\right.
$$

\section{Dendrite Coarsening}

The permeability depends on both $\lambda_{1}$ and $\lambda_{2}$. During unidirectional solidification under a constant temperature gradient and cooling rate, $\lambda_{1}$ may not change after the solidification reaches a steady state ${ }^{[7]}$ while $\lambda_{2}$ undergoes coarsening. $\mathrm{Li}$ and Beckermann ${ }^{[13]}$ found that $\lambda_{2}$ can be estimated by using the interfacial area density $\left(S_{\mathrm{v}}\right)$ through $\lambda_{2}=1.6 / S_{\mathrm{v}}$, where $S_{\mathrm{v}}$ is defined as the interface area divided by the sample volume that contains both the solid and liquid phases. Recently, a general formulation was suggested for $S_{\mathrm{v}}$ that accounts for the effects of growth, curvature-driven coarsening, and interface coalescence ${ }^{[12]}$ :

$$
S_{\mathrm{v}}=f_{\mathrm{s}}\left(1-f_{\mathrm{s}}\right)^{-r}\left(S_{\mathrm{s} 0}^{-3}+K_{0} t\right)^{-b},
$$

where $S_{\mathrm{v}}$ is a function of the local solid volume fraction $\left(f_{\mathrm{s}}=f_{\mathrm{c}}+f_{\beta}\right)$ and time $(t)$. It should be stressed that this $t$ denotes the time from the start of the solidification to the current moment (i.e., the solidification has not yet finished). It is different from $t_{\mathrm{f}}$ (the local solidification time in Eq. [1]), which denotes the duration from the start to the end of solidification. The values of the coarsening parameters $\left(r, S_{\mathrm{s} 0}\right.$, and $\left.K_{0}\right)$ as suggested for Eq. [15] were verified for the crystal growth under pure diffusive conditions. ${ }^{[12]}$ Under stirring conditions by RMF, they may be adapted.

\section{Auxiliary Equations}

The mixture concentrations are calculated according to: $\quad c_{\text {mix }, \mathrm{Si}}=\frac{\left(c_{\ell, \mathrm{Si}} \cdot \rho_{\ell} \cdot f_{\ell}+c_{\mathrm{c}, \mathrm{Si}} \cdot \rho_{\mathrm{c}} \cdot f_{\mathrm{c}}+c_{\beta, S i} \cdot \rho_{\beta} \cdot f_{\beta}\right)}{\left(\rho_{\ell} \cdot f_{\ell}+\rho_{\mathrm{c}} \cdot f_{\mathrm{c}}+\rho_{\beta} \cdot f_{\beta}\right)} \cdot 100 \mathrm{pct} \quad$ and $c_{\text {mix,Fe }}=\frac{\left(c_{\ell, \mathrm{Fe}} \cdot \rho_{\ell} \cdot f_{\ell}+c_{\mathrm{c}, \mathrm{Fe}} \cdot \rho_{\mathrm{c}} \cdot f_{\mathrm{c}}+c_{\beta, \mathrm{Fe}} \cdot \rho_{\beta} \cdot f_{\beta}\right)}{\left(\rho_{\ell} \cdot f_{\ell}+\rho_{\mathrm{c}} \cdot f_{\mathrm{c}}+\rho_{\beta} \cdot f_{\beta}\right)} \cdot 100 \mathrm{pct}$, where $c_{\ell, \mathrm{Si}}$, $c_{\mathrm{c}, \mathrm{Si}}$, and $c_{\beta, \mathrm{Si}}$ are $\mathrm{Si}$ concentrations; $c_{\ell, \mathrm{Fe}}, c_{\mathrm{c}, \mathrm{Fe}}$, and $c_{\beta, \mathrm{Fe}}$ are $\mathrm{Fe}$ concentrations; $\rho_{\ell}, \rho_{\mathrm{c}}$, and $\rho_{\beta}$ are the densities; and $f_{\ell}, f_{\mathrm{c}}$, and $f_{\beta}$ are the volume fractions of the liquid melt, columnar dendrite, and intermetallic precipitate, respectively. Macrosegregation is characterised by the segregation index, $c_{\text {mix }, \mathrm{Si}}^{\text {index }}=\frac{c_{\text {mix }, \mathrm{Si}}-c_{0, \mathrm{Si}}}{c_{0, \mathrm{Si}}}$. $100 \mathrm{pct}$ and $c_{\text {mix }, \mathrm{Fe}}^{\text {index }}=\frac{c_{\text {mix, }}-c_{0, \mathrm{Fe}}}{c_{0, \mathrm{Fe}}} \cdot 100 \mathrm{pct}$.

\section{SIMULATION CONFIGURATION AND CASE DEFINITION}

The configuration of the simulation domain, as shown in Figure 2, is taken from the experimental setup. ${ }^{[25]} \mathrm{A}$ cylindrical sample $(\phi 8 \mathrm{~mm})$ of an AlSi7Fel alloy is solidified unidirectionally in an $\mathrm{Al}_{2} \mathrm{O}_{3}$ crucible. The initial temperature $\left(T_{0}\right)$ of the melt is $1190 \mathrm{~K}$. The Dirichlet boundary conditions are imposed at the top and bottom: $T_{\text {Bottom }}$ starts to decrease with a cooling rate of $0.12 \mathrm{~K} / \mathrm{s}$ from $t=0 \mathrm{~s}$, while $T_{\text {Top }}$ starts to decrease with the same cooling rate from $t=50 \mathrm{~s}$ to maintain a target temperature gradient $(\vec{G})$. The lateral walls of the sample are treated as adiabatic. When the RMF is applied with a constant rotational frequency $(f)$ and magnetic induction $(B)$, the azimuthal component of the induced electromagnetic force $\left(\vec{F}_{\theta}\right)$ can be calculated analytically as follows ${ }^{[26]}$.

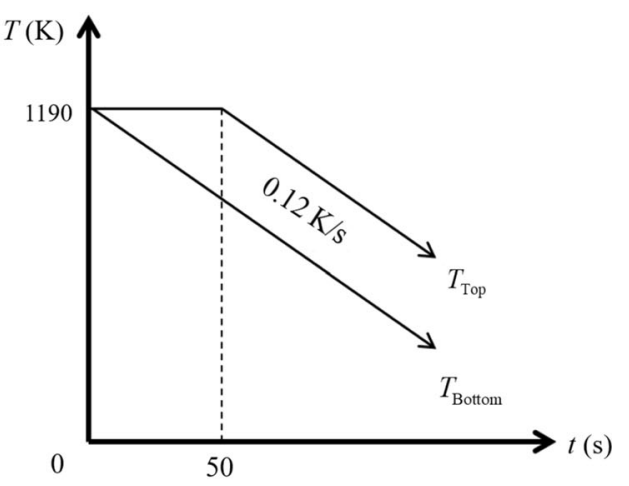

(b)

Fig. 2 - Geometric and boundary conditions of the experimental setup. (a) Schematic for the flow pattern and formation of different phases and (b) cooling conditions at the top and bottom of the sample. 


$$
\vec{F}_{\theta}=\frac{1}{2} \sigma \omega B^{2} r\left(1-\frac{u_{\theta}}{\omega r}\right) \vec{e}
$$

where $\sigma$ is the electrical conductivity of the melt, $\omega=$ $2 \pi f$ is the angular frequency, $B$ is the magnetic induction, $u_{\theta}$ is the azimuthal velocity component of the melt at a radial coordinate $r$, and $\vec{e}$ is the tangential unit vector. The material properties and other parameters can be found in Table I.

As shown in Table II, six simulation cases are designed. Case I is solidified under pure diffusive condition. Cases II and III are designed to verify the consistency between the 2D axisymmetric and full 3D simulations under the forced flow condition, where $\lambda_{2}$ is assumed to be a constant. Due to the high cost of the $3 \mathrm{D}$ simulation, the rest of the simulations are performed only in 2D axisymmetry. Cases IV and V are designed with varying values of $\lambda_{2}$, i.e., considering dendrite coarsening, in which the former is for the ternary alloy and the latter is for the binary alloy. The last case (VI) considers natural convection only, i.e., thermo-solutal convection (TSC), which can be compared with previous cases of forced flow (RMF + TSC).

The model is implemented in ANSYS FLUENT version 17.1, which uses a control-volume finite difference numerical method. For each time step, 30 iterations are adopted to decrease the normalised residuals of concentration, flow quantities, and continuity below $10^{-4}$ and enthalpy quantities below $10^{-7}$. The decision to select a time step that ensures a high accuracy solution must be determined empirically by test simulations. In this study, all calculations are run with a time step of $0.001 \mathrm{~s}$. The maximum mesh sizes are $2.5 \times 10^{-4}$ $\mathrm{m}$ (3D) and $1.5 \times 10^{-4} \mathrm{~m}(2 \mathrm{D})$. One $3 \mathrm{D}$ simulation takes approximately seven weeks, while one 2D simulation takes approximately one week on a high-performance cluster $(2.6 \mathrm{GHz}, 12$ cores).

Table I. Summary of Material Properties and Other Parameters ${ }^{[5,10,12,16]}$

\begin{tabular}{|c|c|c|c|}
\hline Properties/Parameters & Symbol & Units & Values \\
\hline \multicolumn{4}{|l|}{ Thermophysical Properties } \\
\hline Specific Heat & $c_{\mathrm{p}}^{\ell}, c_{\mathrm{p}}^{\mathrm{c}}, c_{\mathrm{p}}^{\beta}$ & $\mathrm{J} \mathrm{Kg}^{-1} \mathrm{~K}^{-1}$ & 1140.0 \\
\hline Latent Heat & $\Delta h_{\mathrm{f}}$ & $\mathrm{J} \mathrm{Kg}^{-1}$ & $4.0 \times 10^{5}$ \\
\hline Diffusion Coefficient (Liquid) & $D_{\ell}$ & $\mathrm{m}^{2} \mathrm{~s}^{-1}$ & $6.45 \times 10^{-9}$ \\
\hline Thermal Conductivity & $k_{\mathrm{n}}^{\ell}, k_{\mathrm{n}}^{\mathrm{c}}, k_{\mathrm{n}}^{\beta}$ & $\mathrm{W} \mathrm{m}^{-1} \mathrm{~K}^{-1}$ & 100.0 \\
\hline Liquid Thermal Expansion Coefficient & $\beta_{\mathrm{T}}$ & $\mathrm{K}^{-1}$ & $-1.85 \times 10^{-4}$ \\
\hline Liquid Solutal Expansion Coefficient & $\beta_{\mathrm{c}}(\mathrm{Si})$ & wt pct ${ }^{-1}$ & $1.3 \times 10^{-3}$ \\
\hline Density & $\rho_{\ell}, \rho_{\mathrm{c}}, \rho_{\beta}$ & $\mathrm{Kg} \mathrm{m}^{-3}$ & 2535.0 \\
\hline Viscosity & $\mu_{\ell}$ & $\mathrm{Kg} \mathrm{m}^{-1} \mathrm{~s}^{-1}$ & $2.52 \times 10^{-3}$ \\
\hline Electrical Conductivity & $\sigma$ & $\Omega^{-1} \mathrm{~m}^{-1}$ & $3.65 \times 10^{6}$ \\
\hline \multicolumn{4}{|l|}{ Thermodynamic Parameters } \\
\hline Concentrations of Binary Eutectic Valley & $c_{\mathrm{eut}, \mathrm{Si}}^{*}, c_{\mathrm{eut}, \mathrm{Fe}}^{*}$ & - & Eqs. [8] and [9] \\
\hline Growth Constant for $\beta-\mathrm{Al}_{5} \mathrm{FeSi}$ & $g_{\beta}$ & $1 / \mathrm{s}$ & 0.1 \\
\hline Ternary Eutectic Temperature & $T_{\mathrm{eu}}$ & $\mathrm{K}$ & 850.0 \\
\hline Liquidus Slope $(\mathrm{Si})$ & $m_{\mathrm{Si}}$ & $\mathrm{K}(\mathrm{wt} \mathrm{pct})^{-1}$ & -6.62 \\
\hline Liquidus Slope (Fe) & $m_{\mathrm{Fe}}$ & $\mathrm{K}(\mathrm{wt} \mathrm{pct})^{-1}$ & -3.93 \\
\hline Equilibrium Partition Coefficient & $k_{\mathrm{Si}}, k_{\mathrm{Fe}}$ & - & $0.13,0.01$ \\
\hline Primary Dendrite Arm Spacing & $\lambda_{1}$ & $\mu \mathrm{m}$ & 300.0 \\
\hline Secondary Dendrite Arm Spacing & $\lambda_{2}$ & $\mu \mathrm{m}$ & coarsening law \\
\hline Gibbs Thomson Coefficient & $\Gamma$ & $\mathrm{m} \mathrm{K}$ & $2.41 \times 10^{-7}$ \\
\hline Melting Point of Solvent & $T_{\mathrm{f}}$ & $\mathrm{K}$ & 935.5 \\
\hline \multicolumn{4}{|l|}{ Coarsening Parameters } \\
\hline Coarsening Exponent & $b$ & - & $1 / 3$ \\
\hline \multirow[t]{3}{*}{ Coarsening Constant } & $r$ & & 0.25 \\
\hline & $S_{\mathrm{S} 0}$ & $\mu \mathrm{m}$ & 2.46 \\
\hline & $K_{0}$ & $\mu \mathrm{m}^{3} / \mathrm{s}$ & 23.5 \\
\hline \multicolumn{4}{|l|}{ Other Parameters } \\
\hline Initial Concentrations & $c_{0, \mathrm{Si}}, c_{0, \mathrm{Fe}}$ & wt pet & $7.0,1.0$ \\
\hline Initial Temperature & $T_{0}$ & $\mathrm{~K}$ & 1190.0 \\
\hline Cooling Rate at Top and Bottom of the Sample & $R$ & $\mathrm{~K} / \mathrm{s}$ & 0.12 \\
\hline Temperature Gradient & $\vec{G}$ & $\mathrm{~K} / \mathrm{m}$ & 3000.0 \\
\hline Magnetic Induction & $B$ & $\mathrm{mT}$ & 6.0 \\
\hline Angular Frequency of Magnetic Field & $\omega$ & $\mathrm{rad} / \mathrm{s}$ & 314.0 \\
\hline Rotating Frequency of Magnetic Field & $f$ & $\mathrm{~Hz}$ & 50.0 \\
\hline Blocking Effect Constants in Eqs. [11] through [12] & $\beta_{\mathrm{P}}, \beta_{\mathrm{N}}$ & - & 15,10 \\
\hline
\end{tabular}


Table II. Simulations of the AISi7Fe1 Alloy

\begin{tabular}{lllc}
\hline Case & Diffusive vs. RMF & Ternary $\left(\beta-\mathrm{Al}_{5} \mathrm{FeSi}\right)$ vs. Binary & Coarsening Law vs. Constant $\lambda_{2}$ \\
\hline I & diffusive & 2D axis. ternary $\left(\beta-\mathrm{Al}_{5} \mathrm{FeSi}\right)$ & coarsening law \\
II & flow (RMF + TSC) & 3D ternary $\left(\beta-\mathrm{Al}_{5} \mathrm{FeSi}\right)$ & $\lambda_{2}=120 \mu \mathrm{m}$ \\
III & flow (RMF+ TSC) & 2D axis. ternary $\left(\beta-\mathrm{Al}_{5} \mathrm{FeSi}\right)$ & coarsening law \\
IV & 2D axis. ternary $\left(\beta-\mathrm{Al}_{5} \mathrm{FeSi}\right)$ & coarsening law \\
V & flow (RMF+ TSC) & 2D axis. binary & coarsening law \\
VI & 2lowly TSC) & 2D axis. ternary $\left(\beta-\mathrm{Al}_{5} \mathrm{FeSi}\right)$ & \\
\hline
\end{tabular}

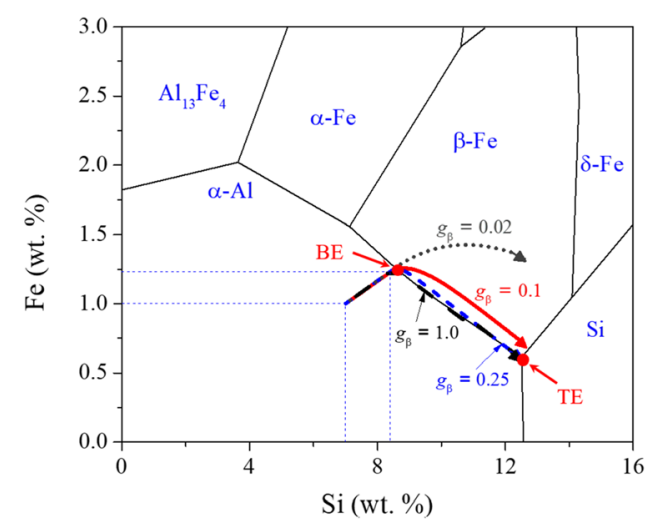

(a)

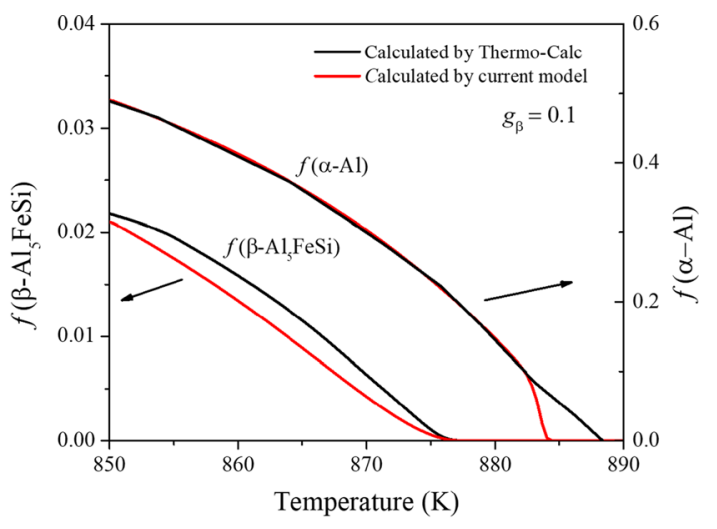

(b)

Fig. 3-Thermodynamics (phase diagram) of AlSi7Fel and calculated solidification path for Case I. (a) Evolution of solute concentrations ( $c_{\ell, \mathrm{Fe}}$, $\left.c_{\ell, \mathrm{Si}}\right)$ when $g_{\beta}$ takes different values. (b) Comparison of the evolution of the phases calculated with the current solidification model and with the commercial software Thermo-Calc.

\section{SIMULATION RESULTS}

\section{A. Dendrite Coarsening and Formation of $\beta-\mathrm{Al}_{5} \mathrm{FeSi}$}

The calculated solidification path of the ternary alloy AlSi7Fel considering the formation of $\beta-\mathrm{Al}_{5} \mathrm{FeSi}$, based on Case I, is compared with the thermodynamic analysis by the commercial software Thermo-Calc, as shown in Figure 3. The Al-rich corner of the $\mathrm{Al}-\mathrm{Si}-\mathrm{Fe}$ phase diagram is shown in Figure 3(a), where the red solid line indicates the calculated solidification path by the current model (assuming the growth constant for $\beta-\mathrm{Al}_{5} \mathrm{FeSi}$, $\left.g_{\beta}=0.1\right)$. The calculated concentrations of $\mathrm{Si}$ and $\mathrm{Fe}$ are exported along the axis of the sample. The solidification starts with the development of the primary aluminium phase $(\alpha-\mathrm{Al})$, and the $\mathrm{Si}$ and $\mathrm{Fe}$ elements are rejected into the rest of the melt which enriches their concentrations. As their concentrations reach the binary eutectic point BE, binary eutectic reaction starts, $L \rightarrow \alpha-\mathrm{Al}+\beta-\mathrm{Al}_{5} \mathrm{FeSi}^{\left[{ }^{19-21]}\right.}$ The formed $\alpha$-Al is considered to be the further growth of the primary aluminium phase, and the intermetallic phase $\left(\beta-\mathrm{Al}_{5} \mathrm{FeSi}\right)$ precipitates as a secondary phase. A large amount of $\mathrm{Fe}$ in the rest of the melt is consumed, and the solidification path turns towards the direction of the ternary eutectic point TE at $850 \mathrm{~K}$, then ternary reaction occurs, $L \rightarrow \alpha-\mathrm{Al}+\beta-\mathrm{Al}_{5} \mathrm{FeSi}^{\left[{ }^{[19-21]}\right.}$ The solidification path during the formation of binary eutectic is almost parallel (not identical) to the binary eutectic valley of the phase diagram (thermodynamic equilibrium). The deviation between the simulation and the equilibrium data can be attributed to the growth kinetics of $\beta-\mathrm{Al}_{5} \mathrm{FeSi}$, i.e., the value of $g_{\beta}$. Thus, calculated solidification paths with different values of $g_{\beta}$ (from 0.02 to 1.0) are compared in Figure 3(a). The larger the value of $g_{\beta}$, i.e., the faster (or easier) the growth of $\beta-\mathrm{Al}_{5} \mathrm{FeSi}$, the closer the calculated solidification path is to the thermodynamic equilibrium one. This is further discussed in Section V.

The calculated phase fractions obtained by using the current numerical model and the thermodynamic equilibrium data (Thermo-Calc) are compared, as shown in Figure $3(\mathrm{~b})$. The initial temperature of the primary aluminium phase $(\alpha-\mathrm{Al})$ is approximately $4.3 \mathrm{~K}$ lower than the equilibrium liquidus temperature $(888.4 \mathrm{~K})$. This is due to the growth kinetics of the columnar primary dendrite tip. ${ }^{[18]}$ In the later stage of solidification, the calculated phase fractions of $\alpha$-Al are almost identical between the two models. The numerically calculated phase fraction of $\beta-\mathrm{Al}_{5} \mathrm{FeSi}$ is smaller than that predicted by Thermo-Calc.

Under the pure diffusive crystal growth condition (Case I), the evolution of the microstructure considering coarsening is also evaluated. The specific interfacial area $\left(S_{\mathrm{v}}\right)$ and the corresponding $\lambda_{2}$ as a function of the local solid volume fraction $\left(f_{\mathrm{s}}=f_{\mathrm{c}}+f_{\beta}\right)$ are shown in Figure 4(a). At the columnar dendrite tips, according to both the experimental observation and numerical model, ${ }^{[12]}$ there should be no side branches. Thus, $\lambda_{2}$ 


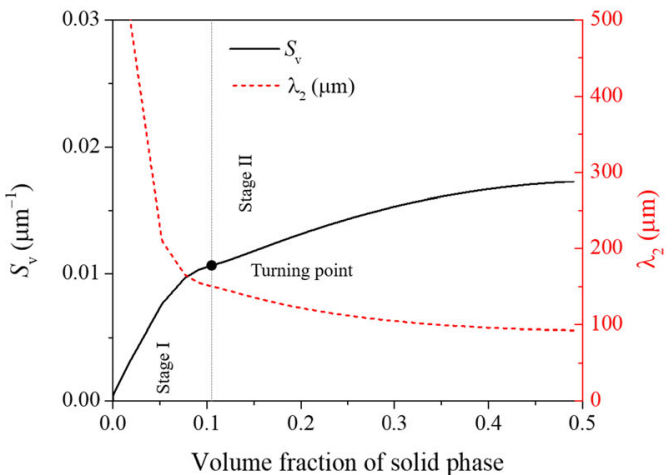

(a)

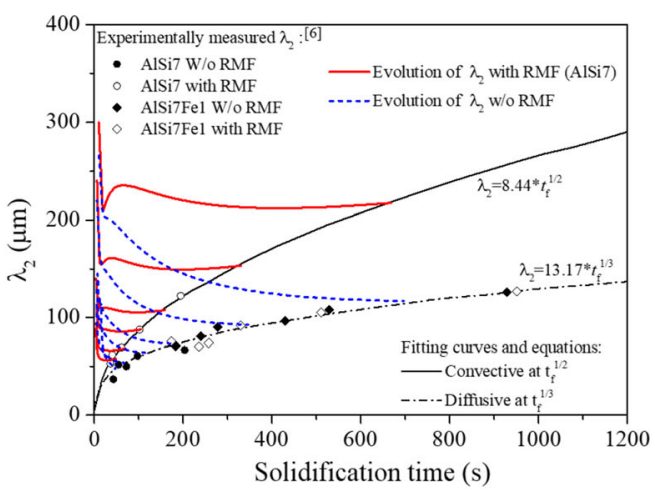

(b)

Fig. 4-Microstructure evolution of Case I. (a) The specific interfacial area $\left(S_{\mathrm{v}}\right)$ and $\lambda_{2}$ as a function of the local solid volume fraction. (b) The evolution of $\lambda_{2}$ with time. In $(b)$, further simulation cases are included to study the effect of forced flow and intermetallic precipitates $\left(\beta\right.$ - $\left.\mathrm{Al} \mathrm{l}_{5} \mathrm{FeSi}\right)$ on the evolution of $\lambda_{2}$. The black circles and squares are the experimentally measured $\lambda_{2}$ of the as-solidified state with/without RMF; the black lines are the fitting curves. The red and blue lines are the calculated $\lambda_{2}$ evolutions with RMF (Case V) and without RMF (Case I), respectively.

starts from a large value and is followed by a drastic decrease. By contrast, $S_{\mathrm{v}}$ starts from a small value and is followed by a steep increase. The reason for this rapid decrease in $\lambda_{2}$ and corresponding increase in $S_{\mathrm{v}}$ is due to high undercooling. This period is called stage I according to Neumann-Heyme, ${ }^{12]}$ corresponding to the initial free dendritic growth and side-branch extension. After the turning point as marked in Figure 4(a), the solidification is characterised by concurrent growth and coarsening without significant interface coalescence (stage II), during which the increase rate of $S_{\mathrm{v}}$ and decrease rate of $\lambda_{2}$ decelerate. Since the eutectic reaction occurs after $f_{\mathrm{s}}=0.5$ (Figure 3(b)), stage III, during which coalescence of the interfaces leads to a decrease in $S_{\mathrm{v}}$, is not observed in the current case.

The transient evolution of $\lambda_{2}$ during solidification (red solid and blue dash lines) and the experimentally measured $\lambda_{2}$ of the as-solidified state (black circles and squares) are plotted in Figure 4(b). The experiments were conducted by Steinbach et al. ${ }^{[6]}$ on the AlSi7 and AlSi7Fe1 alloys with and without RMF. Two equations were obtained by fitting their experimental results: $t_{\mathrm{f}}=8.44 * t_{\mathrm{f}}^{1 / 2}$ for the AlSi7 alloy under RMF, and $t_{\mathrm{f}}=13.17 * t_{\mathrm{f}}^{1 / 3}$ for both the AlSi7 alloy without RMF and the AlSi7Fel alloy with RMF. The simulation results of the coarsening process are shown as blue dash lines in Figure 4(b). The simulation results of Case V (red solid lines), which is conducted under RMF on the binary alloy AlSi7, are also included here for further discussion in Section V. It is still unclear how the secondary dendrites initiate and what the initial value for $\lambda_{2}$ is. In the current study, a simple assumption is made that $\lambda_{2}$ starts to develop at the position $300 \mu \mathrm{m}$ $\left(\sim \lambda_{1}\right)$ from the tips of the primary dendrites. As depicted in Figure 4(b), different blue dash lines denote the evolution of $\lambda_{2}$ at different cooling rates. For all cases, $\lambda_{2}$ has a large value at the beginning of the solidification, and then decreases gradually. As expected, the final values of $\lambda_{2}$ (ends of blue lines) fall on the curve of $\lambda_{2}=13.17 * t_{\mathrm{f}}^{1 / 3}$, following the classical coarsening law with $\mathrm{b}=1 / 3$.

\section{B. Directional Solidification Under Forced Convective Conditions}

\section{Flow pattern and solidification}

The calculated solidification sequences of Case II (full 3D calculation) and Case III (axisymmetric calculation) are shown in Figure 5 for comparison. In both cases, RMF is applied. An azimuthal flow $(\sim 24.1 \mathrm{~mm} / \mathrm{s})$ and a meridional flow $(\sim 9.0 \mathrm{~mm} / \mathrm{s})$ as induced by the Ekman effect are generated. As shown in Figures 5(a) and (c), the fluid rotates and moves downwards near the sample surface, and then rotates and moves upwards along the centreline of the sample. The flow pattern in the mushy zone is similar to that in the bulk liquid, although the fluid flow is suppressed by the dendrites to a low magnitude. ${ }^{[5]}$ As demonstrated by the iso-surface in Figure 5(a), the solute-enriched interdendritic liquid is swept to the centre of the sample, leading to the formation of a central macrosegregation channel with some sidearms. The shape of the central segregation is sometimes referred to as "Christmas tree". This kind of segregation distribution has been repeatedly observed in experiments. ${ }^{[27]}$ The accumulation of the solute in the central part decreases the liquidus temperature of the melt, and hence delays (slows down) the local solidification. As shown in Figure 5(b), there is a hollow tube in the centre, which is filled with the solute-enriched melt. The 2D axisymmetric calculation (Figure 5(d)) can successfully reproduce the full $3 \mathrm{D}$ calculation (Figures 5(b) through (c)). Therefore, the subsequent parameter studies presented in the following sections are conducted with the $2 \mathrm{D}$ axisymmetric calculations.

\section{Model validation}

The experiment-simulation comparison of macrosegregation based on Case IV is presented in Figures 6(a) and (b). Mikolajczak and Ratke carried out a series of unidirectional solidification experiments to study the effect of RMF on the formation and distribution of $\beta$ - $\mathrm{Al}_{5} \mathrm{FeSi}$ in $\mathrm{Al}-\mathrm{Si}-\mathrm{Fe}$ alloys. ${ }^{[4,25]}$ The configuration of their experiments (including the temperature gradient, withdrawal velocity, RMF intensity and frequency) is 


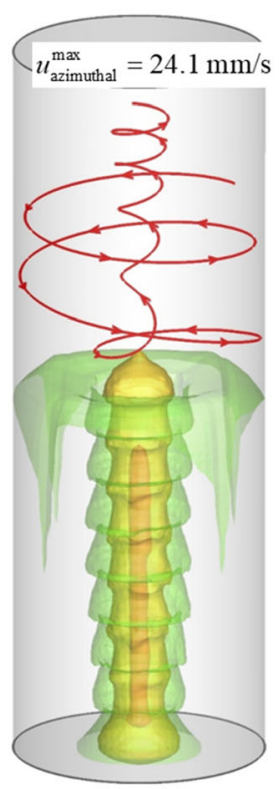

(a)

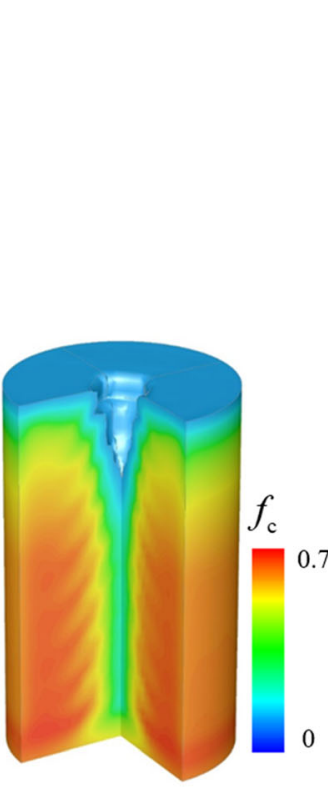

(b)

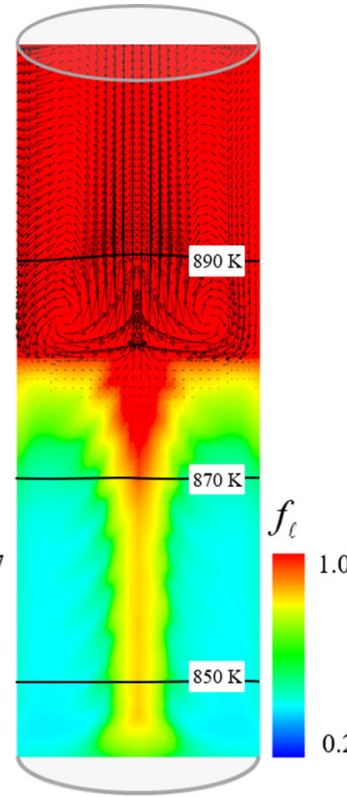

(c)

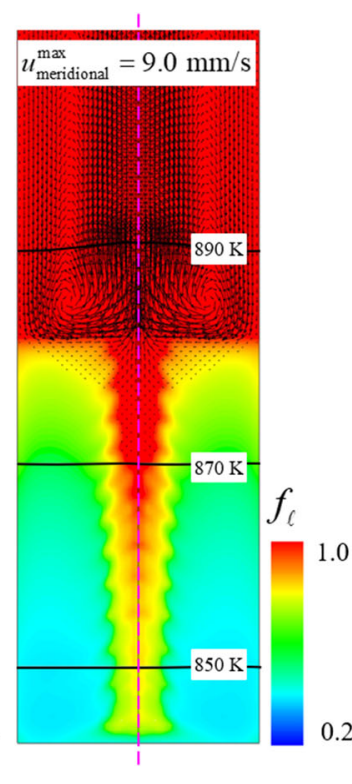

(d)

Fig. 5-Solidification sequence of the sample under RMF at $550 \mathrm{~s}$ : (a) through $(c)$ Case II with full 3D calculation and $(d)$ Case III with 2D axisymmetric calculation. (a) Iso-surfaces of $\mathrm{Si}$ macrosegregation index $\left(c_{\text {mix.Si }}^{\text {index }}\right)$ : the innermost iso-surface (orange) is for $c_{\text {mix.Si }}^{\text {index }}=43$ pct, the middle one (yellow) for $c_{\text {mix }}^{\text {index }}=14$ pct, the outermost (green) for $c_{\mathrm{mix} S i}^{\text {index }}=-3$ pct; one streamline is drawn to show the flow. (b) Contour of the columnar phase fraction $\left(f_{\mathrm{c}}\right)$ in two vertical sections and one iso-surface of $f_{\mathrm{c}}=0.01$ on the top indicating the position of the columnar tip front. (c) Contour of $f_{\ell}$ (colour scaled) along the centre of the longitudinal section, overlaid with isotherms and vectors of the meridional flow. (d) Same result as (c) but in a 2D axisymmetric calculation (one half section is mirrored from the other) (Color figure online).

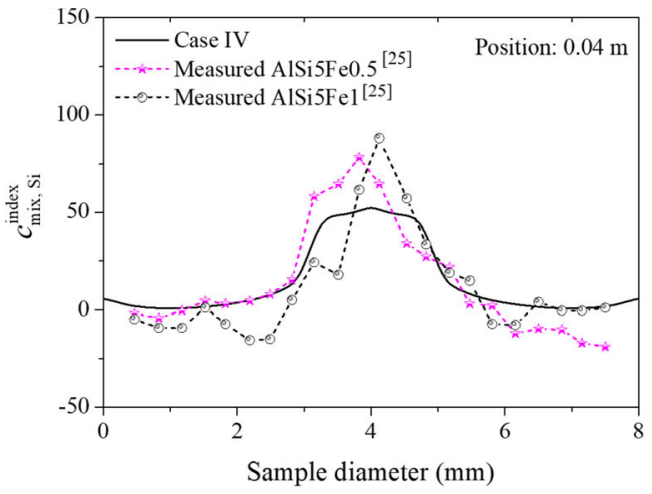

(a)

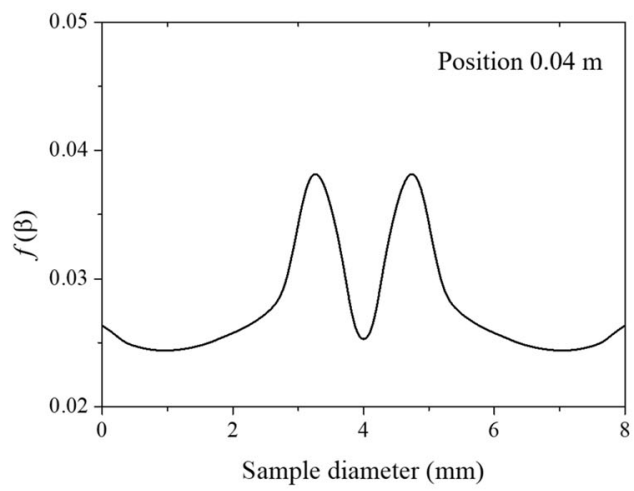

(c)

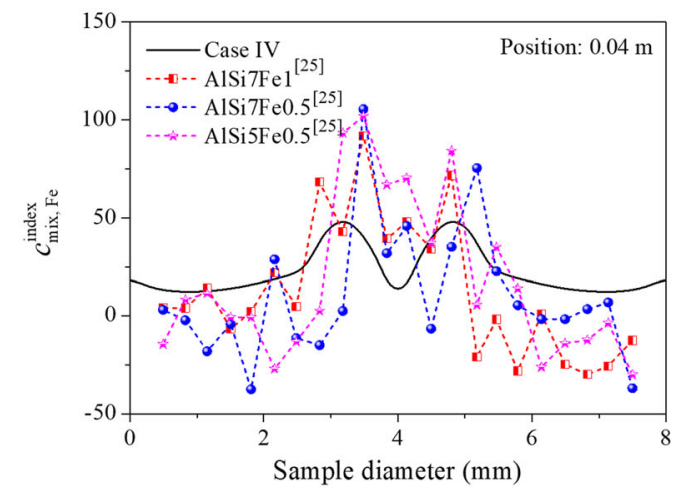

(b)

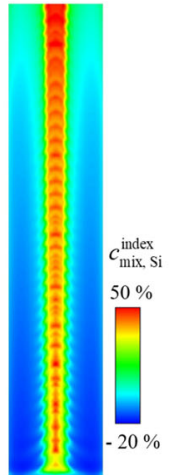

(d)

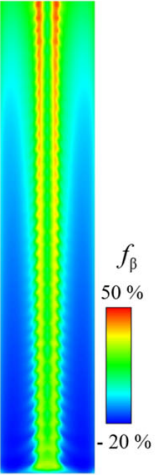

(e)

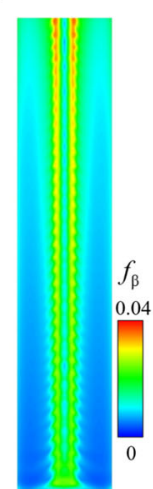

(f)

Fig. 6-Experiment-simulation comparison. Radial distribution of the segregtion indexes of $(a) \mathrm{Si}\left(c_{\operatorname{mix}}^{\text {index }}\right)$ and $(b)$ Fe $\left(c_{\text {mix.Fe }}^{\text {index }}\right)$ along the sample diameter. (c) Distribution of $\beta-\mathrm{Al}_{5} \mathrm{FeSi}$ along the sample diameter. Contours of $(d) c_{\text {mix }, \mathrm{Si}}^{\text {index }},(e) c_{\text {mix. } \mathrm{Fe}}^{\text {index }}$, and $(f) f(\beta)$. 

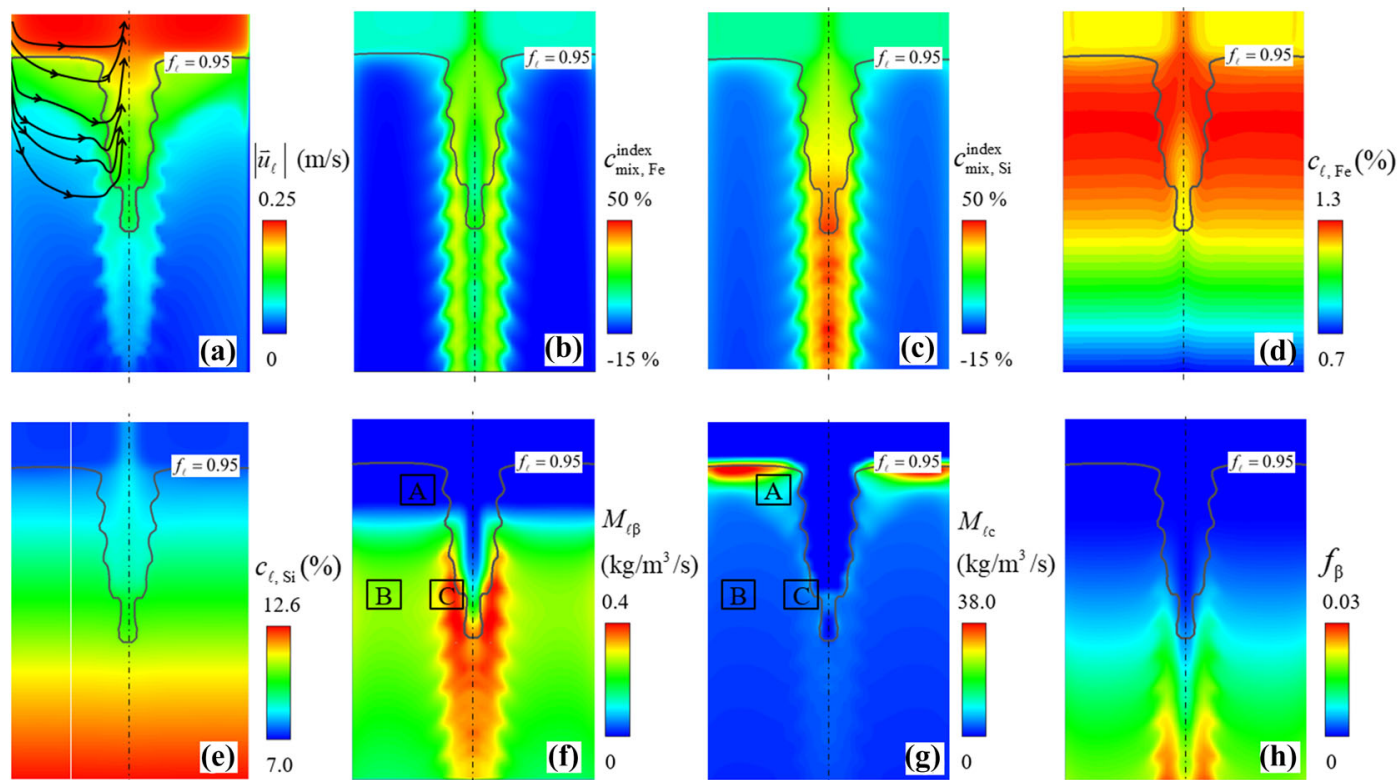

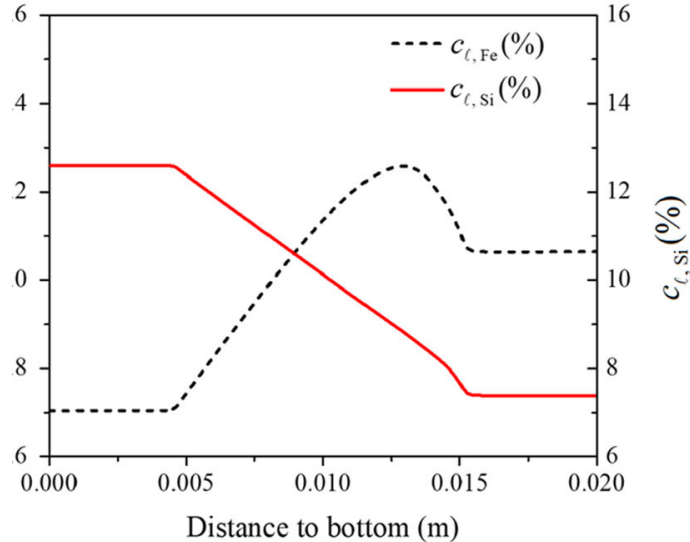

(i)

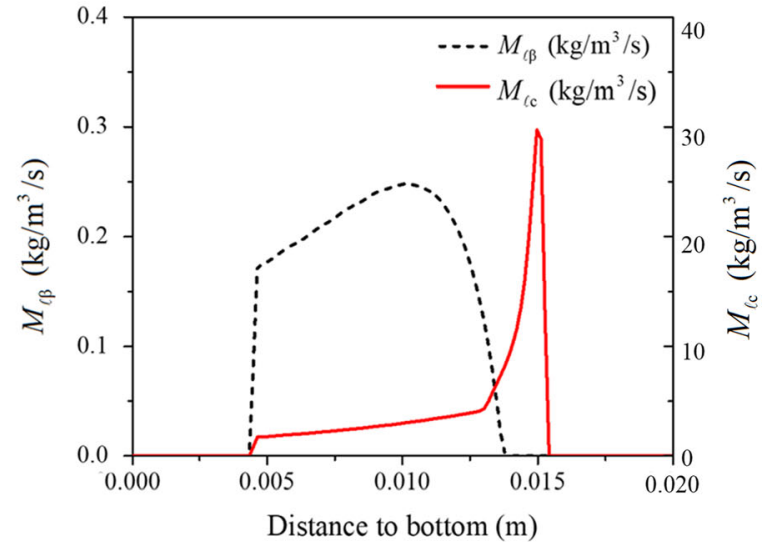

(j)

Fig. 7-Analysis of the solidification sequence and the formation/distribution of $\beta-\mathrm{Al}_{5} \mathrm{FeSi}$ at $t=600 \mathrm{~s}$ for Case IV. The black solid isopleth in (a) through $(h)$ denotes the solidification front $\left(f_{\ell}=0,95\right)$, and the bottom of these figures coincides with the position of the ternary eutectic isotherm $(850 \mathrm{~K})$. (a) Liquid velocity magnitude $\left(\vec{u}_{\ell}\right)$ overlaid by streamlines of the meridional flow; macrosegregation indices for (b) Fe $\left(c_{\text {mix }}^{\text {index }}\right)$ and (c) Si $\left(c_{\text {mix }}^{\text {ind }}\right)$; liquid concentrations of (d) $\mathrm{Fe}\left(c_{\ell \mathrm{Fe}}\right)$ and (e) $\mathrm{Si}\left(c_{\ell \mathrm{Si}}\right)$; mass transfer rates (f) from liquid to intermetallic precipitates $\left(M_{\ell \beta}\right)$ and $(\mathrm{g})$ from liquid to columnar phase $\left(M_{\ell \mathrm{c}}\right) ;(\mathrm{h})$ volume fraction of intermetallic precipitates $\left(f_{\beta}\right)$; (i) liquid concentration profiles and (j) mass transfer rate profiles along the middle radius of the sample (as marked by the white solid line in (e)).

identical to what was used in this study. EDX analysis was made to determine the solute concentration distribution across the as-solidified sample section. The macrosegregation distributions along the diameter of the sample are displayed in Figures 6(a) and (b). Very good agreement between the experimental and the calculated results is obtained. As shown in Figure 6(a), both simulation and experimental results show that the centre of the sample is positively segregated and the periphery is negatively segregated. The maximum value of $c_{\text {mix.Si }}^{\text {index }}(\sim 52.7 \mathrm{pct})$ is observed at the centreline of the sample. The segregation index profile of $\mathrm{Fe}, c_{\text {mix }}^{\text {index }}$, is presented in Figure 6(b). In contrast to the distribution of $c_{\text {mix }, \mathrm{Si}}^{\text {index }}$, the maximum of $c_{\text {mix }, \mathrm{Fe}}^{\text {index }}(\sim 48.3 \mathrm{pct})$ is not observed at the centreline of the sample, but at approximately $1 \mathrm{~mm}$ from the centreline. The current simulation results are different from those of previous studies, ${ }^{[16,28]}$ in which Fe exhibited the same segregation pattern as $\mathrm{Si}$. The final distribution of the volume fraction of $\beta-\mathrm{Al}_{5} \mathrm{FeSi}\left(f_{\beta}\right)$ is shown in Figure 6(c). The distribution pattern of $\beta-\mathrm{Al}_{5} \mathrm{FeSi}$ is similar to that of $c_{\text {mix. }}^{\text {inde }}$, indicating that $\mathrm{Fe}$ is mainly solidified in the form of intermetallic precipitates. The corresponding contours of $c_{\text {mix.Si }}^{\text {index }}, \quad c_{\text {mix.Fe }}^{\text {index }}$, and $f_{\beta}$ are displayed in Figures 6(e) through (g). Si is accumulated in the central segregation channel, $\mathrm{Fe}$ is concentrated in the sidearms beside the central channel, and the distribution of $\beta$ - $\mathrm{Al}_{5} \mathrm{FeSi}$ is similar to that of $\mathrm{Fe}$. Due to the forced flow under the RMF, the solute-enriched liquid is continuously transported to the bulk liquid. 


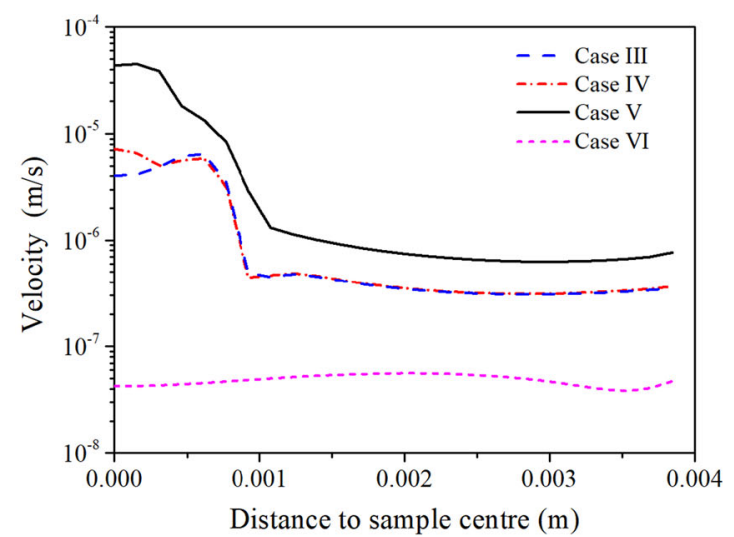

(a)

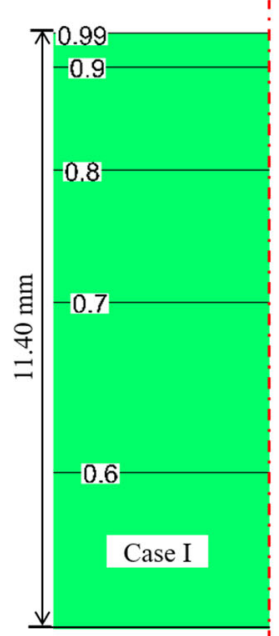

(c)

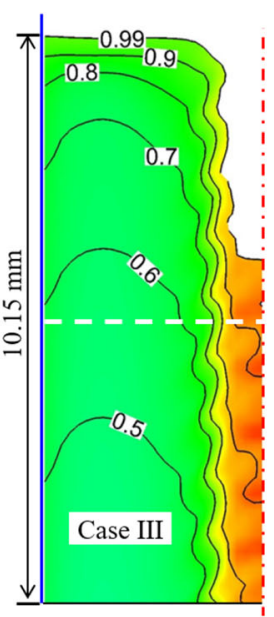

(d)

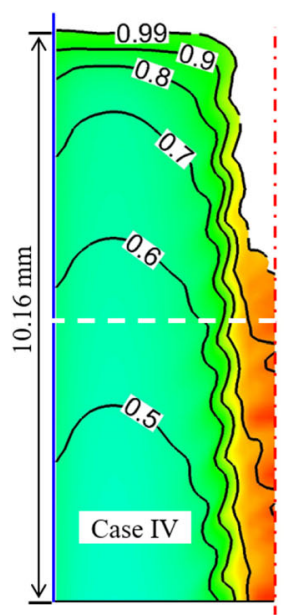

(e)

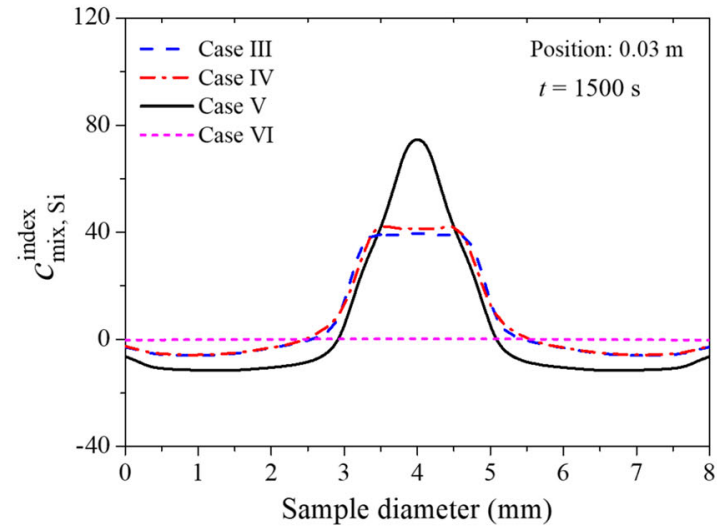

(b)

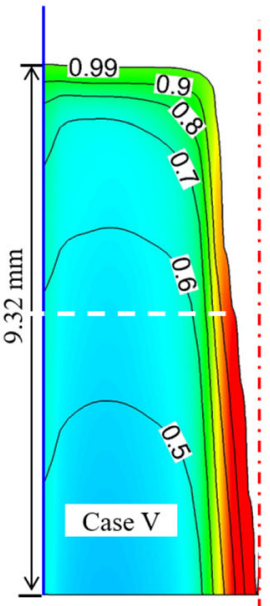

(f)

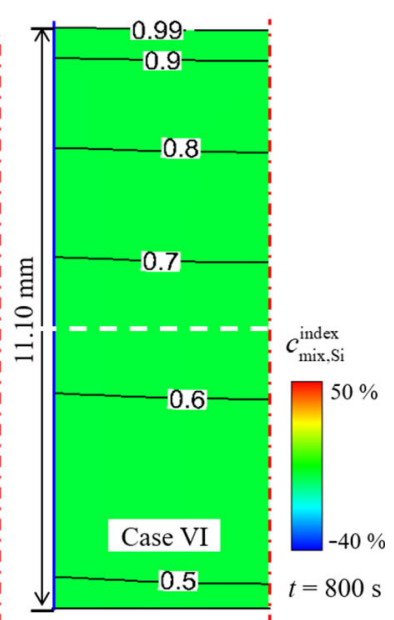

(g)

Fig. 8-Calculation results of the mushy zone for all simulation cases (except for Case II) at $t=800 \mathrm{~s}$. (a) Comparison of the liquid velocity magnitude at the middle height of the mush (marked by white dash lines). (b) Macrosegregation index of Si along the diameter of the sample after the sample is fully solidified. $(c)$ through $(g)$ Contours of $c_{\text {mix.Si }}^{\text {index }}$ overlaid with isopleths of $f_{\ell}$, with the mushy zone thickness marked on the left of each figure.

\section{Formation of intermetallic precipitates} during solidification under RMF

The simulation results of Case IV at $t=600 \mathrm{~s}$ are shown in Figure 7. Since the interdendritic liquid prefers to take the path with a higher liquid volume fraction, streamlines near the sidearms of the central channel are twisted/distorted, as evident in Figure 7(a). This kind of flow transports solute-enriched liquid from the periphery of the sample to the central part, forming the central segregation channel, as shown by $c_{\text {mix, Fe }}^{\text {index }}$ and $c_{\text {mix }, \text { Si }}^{\text {index }}$ in Figures 7(b) and (c). Some solute-enriched liquid is further transferred into the bulk liquid, enriching the solute in the bulk liquid. In contrast to $\mathrm{Si}, \mathrm{Fe}$ is less segregated along the centreline of the sample. As shown in Figure $7(\mathrm{~d}), c_{\ell, \mathrm{Fe}}$ starts with an increase near the solidification front due to solute rejection during the formation of the primary aluminium dendrites, until it reaches a maximum value $\left(c_{\ell, \mathrm{Fe}}=1.29 \mathrm{pct}\right)$. Since the formation of $\beta-\mathrm{Al}_{5} \mathrm{FeSi}$ by the binary eutectic reaction consumes a large amount of $\mathrm{Fe}, c_{\ell \text {.Fe }}$ gradually decreases until the ternary eutectic reaction occurs. This can also be clearly observed in Figure 7(i). The liquid concentration of $\mathrm{Si}\left(c_{\ell, \mathrm{Si}}\right)$ is displayed in Figures 7(e) and (i). Although the formation of $\beta-\mathrm{Al}_{5} \mathrm{FeSi}$ also consumes a considerable amount of $\mathrm{Si}$, due to the massive rejection of $\mathrm{Si}$ during the solidification of $\alpha-\mathrm{Al}, c_{\ell, \mathrm{Si}}$ increases consistently until the ternary eutectic point. The mass transfer rates from the liquid to $\beta-\mathrm{Al}_{5} \mathrm{FeSi}\left(M_{\ell \beta}\right)$ and to the columnar phase $\left(M_{\ell \mathrm{c}}\right)$ are presented in Figures 7(f), (g), and (j). In the upper part of the mushy zone (A in Figures 7(f) and (g)), only $\alpha$-Al develops. As the solidification path reaches the binary eutectic valley, $\beta-\mathrm{Al}_{5} \mathrm{FeSi}$ starts to precipitate. In the periphery region (B in Figure 7(f)), due to the low liquid volume fraction and small $c_{\ell, \mathrm{Fe}}$ (Figures 5(c) and (d)), $M_{\ell \beta}$ is small $\left(\sim 0.15 \mathrm{Kg} / \mathrm{m}^{3} / \mathrm{s}\right)$. Near the central channel (C in Figure 7(f)), where $c_{\ell, \mathrm{Fe}}$ is large and the liquid volume fraction is high, $M_{\ell \beta}$ is quite large $\left(\sim 0.4 \mathrm{Kg} / \mathrm{m}^{3} / \mathrm{s}\right)$. In contrast to $M_{\ell \beta}$, the value of $M_{\ell \mathrm{c}}$ reaches a maximum near the solidification front at a value of $38.6 \mathrm{Kg} / \mathrm{m}^{3} / \mathrm{s}$, and then sharply drops to a value of $5.0 \mathrm{Kg} / \mathrm{m}^{3} / \mathrm{s}$. As shown in Figure 7(h), the volume fraction of $\beta-\mathrm{Al}_{5} \mathrm{FeSi}$ 
gradually increases as the solidification progresses. The intermetallic phase increases faster in the centre part than in the periphery of the sample. Most of $\beta-\mathrm{Al}_{5} \mathrm{FeSi}$ forms near the sidearms of the central channel. The maximum value of $f_{\beta}$ is 0.034 .

\section{Effect of intermetallic phases on solidification}

The simulation results of the mushy zone for all the cases (except for Case II) are compared, as shown in Figure 8. The dendrite coarsening parameters as used in Eq. [15] and listed in Table I are only valid for Case I (crystal growth by diffusion). They are assumed to be valid for the cases where $\beta-\mathrm{Al}_{5} \mathrm{FeSi}$ exist and the flow is significantly blocked. As reported by Steinbach et al., ${ }^{[2,6]}$ the ripening exponent $(b)$ changed from $1 / 3$ to $1 / 2$ under the influence of an RMF for the AlSi7 binary alloy (without $\beta-\mathrm{Al}_{5} \mathrm{FeSi}$ ). Neumann-Heyme et al. ${ }^{[12]}$ indicated that $K_{0}$ in Eq. [15] is dependent on the flow condition, cooling rate, and alloy composition. In the current study, a numerical parameter study is carried out to determine the value of $K_{0}$ under the RMF condition. In Case V, b changes from $1 / 3$ to $1 / 2$, and a value of $4.6 \mu \mathrm{m}^{3}$ is used for $K_{0}$. The evaluation of $K_{0}$ for Case $\mathrm{V}$ is further discussed in Section V. In the other cases, $b$ and $K_{0}$ use the original values that are listed in Table I.

A quantitative analysis of the interdendritic flow along the radial direction at the mid-height of the mush thickness is presented in Figure 8(a). There is no velocity for Case I. For all the cases under RMF, the forced flow transports the solute-enriched liquid to the centre, and hence lowers the melting point there. Since $f_{\ell}$ is higher in this region, the flow permeability is higher. In Cases III-V, the liquid velocity at the centre is much larger than that at the periphery region. The flow of Case III is almost the same as that of Case IV. The flow in the central part of Case $\mathrm{V}$ is larger by one order of magnitude than those of Cases III and IV. A consideration of the formation of the intermetallic precipitates is the critical factor for the flow calculation, as the permeability is directly influenced by the intermetallic precipitates, ${ }^{[10]}$ according to Eqs. [11] and [12]. If the sample is solidified under TSC without RMF (Case VI), the flow is very weak $\left(\sim 10^{-8} \mathrm{~m} / \mathrm{s}\right)$. After the sample is fully solidified, $c_{\text {mix,Si }}^{\text {index }}$ along the diameter of the sample for all cases is analysed, as shown in Figure 8(b). The value of $c_{\text {mix,Si }}^{\text {index }}$ in Case $\mathrm{V}$ with the binary alloy (A1Si7) is evidently higher than those in Cases III and IV with the ternary alloy (AlSi7Fe1), although the same RMF is applied. This result can be explained by the block effect on the flow due to the formed intermetallic precipitates in Cases III and IV. The value of $c_{\text {mix.Si }}^{\text {index }}$ in Case III is slightly smaller than that in Case IV. Under the TSC conditon, the segregation is negligible $\left(c_{\text {mix }, \mathrm{Si}}^{\text {index }} \approx \pm 2 \mathrm{pct}\right)$.

The thicknesses of the mushy zone and the corresponding contours of $c_{\text {mix.Si }}^{\text {index }}$ are shown in Figures $8(c)$ through $(\mathrm{g})$. The simulation results of Case I (pure diffusive condition) is shown in Figure 8(c). There is no flow and no macrosegregation. This case has the largest mushy zone thickness $(11.4 \mathrm{~mm})$, which is calculated as the height from the eutectic isotherm to the solidification front $\left(f_{\ell}=0.99\right)$. Figure $8(\mathrm{f})$ shows the simulation results of another extreme case of the binary alloy, e.g., Case $\mathrm{V}$, where there is no $\beta-\mathrm{Al}_{5} \mathrm{FeSi}$ to block the flow. In this case, the flow is relatively strong in the mushy zone (Figure $8(\mathrm{a}))$. The strongest segregation index $\left(c_{\operatorname{mix}, \mathrm{Si}}^{\mathrm{index}}\right)$ is observed and the minimum mushy zone thickness $(9.32$ $\mathrm{mm}$ ) is obtained. Figure $8(\mathrm{~d})$ presents the simulation results of Case III, which emphasises the necessity of considering the dependence of $f_{\beta}$ on the locally varying composition of $\mathrm{Fe}$ and $\mathrm{Si}$. Although the mushy zone thickness ( $\delta=10.15 \mathrm{~mm}$ ) of Case III is still not as thick as that of Case I, it is much thicker than the mushy zone of Case V. A central segregation channel/tube is still observed, but the severity of the segregation is significantly lower than that of Case V. Figure 8(e) presents

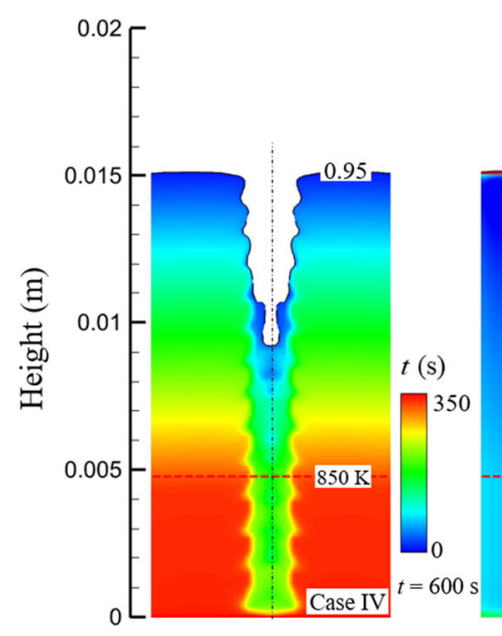

(a)

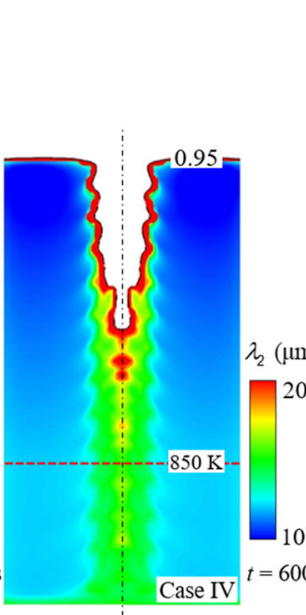

(b)

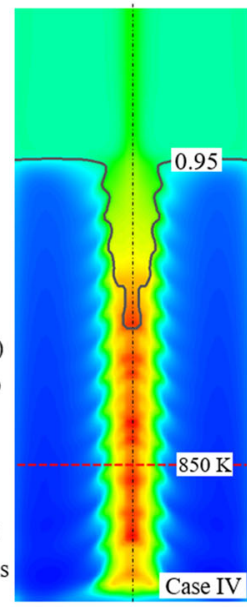

(c)

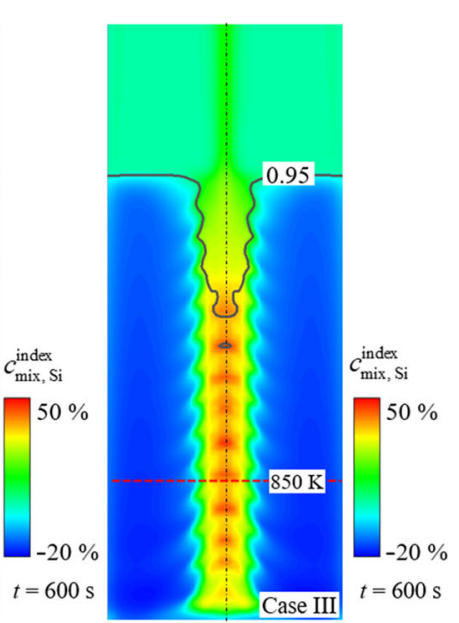

(d)

Fig. 9-Effect of dendrite coarsening on macrosegregation. Simulation results of $(a)$ through $(c)$ Case IV and $(d)$ Case III. One iso-line of $f_{\ell}=$ 0.95 indicates the solidification front, and the red dash lines are isotherms of the eutectic temperature. Contours of (a) $t$, i.e., the duration of the solidification from the formation of the first local solid, (b) calculated $\lambda_{2}$, and (c) through (d) $c_{\text {mix }, S i}$. 


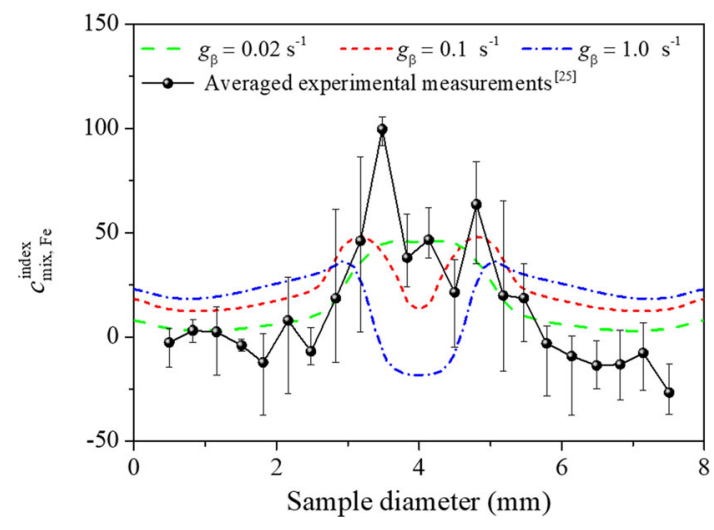

Fig. 10-Effect of $g_{\beta}$ on the distribution profile of $c_{\text {mix }, \mathrm{Fe}}^{\text {index }}$ (Case IV) and comparison with experimental results.

the simulation results of Case IV, which is conducted to reveal the effect of dendrite coarsening. There is almost no difference in the mushy zone thickness and macrosegregation between Cases III and IV. The mushy zone thickness of Case VI is shown in Figure 8(g). In terms of the mushy zone thickness and macrosegregation, the simulation results of Case VI are very similar to that of Case I due to the weak fluid flow.

\section{Effect of dendrite coarsening on solidification}

The simulation results of Case IV are presented in Figure 9. Figure 9(a) shows the duration of the local solidification. At the periphery of the sample, it takes approximately $345 \mathrm{~s}$ from the beginning of solidification to reach the eutectic reaction. In the centre, the solute accumulation delays the solidification, and the solidification process requires approximately $155 \mathrm{~s}$. The calculated value of $\lambda_{2}$ is shown in Figure 9(b). The value of $\lambda_{2}$ is relatively large $(>200 \mu \mathrm{m})$ at the sample centre, while at the periphery, the value of $\lambda_{2}$ is relatively small $(\sim 120$ $\mu \mathrm{m})$. A comparison of $c_{\text {mix,Si }}^{\text {index }}$ between Case III and Case IV is made, as shown in Figures 9(c) and (d). A consideration of dendrite coarsening enhances the central positive segregation $\left(c_{\text {mix }, \mathrm{Si}}^{\text {index }}\right)$ by approximately 4 pct.

\section{DISCUSSION}

The morphology of the intermetallic precipitates $\left(\beta-\mathrm{Al}_{5} \mathrm{FeSi}\right)$ is very complex. It can be curved, bent, branched, hole-shaped, and with imprints. ${ }^{[4,10,20]}$ The growth kinetics of the precipitates with such complex morphologies is unclear. As a first attempt, a simple formulation for the growth of $\beta-\mathrm{Al}_{5} \mathrm{FeSi}$ is introduced in this work (Eq. [10]). All unknown factors contributing to its growth are treated as a growth constant $g_{\beta}$. As shown in Figure 3(a), the value of $g_{\beta}$ significantly influences the solidification path. A very large $g_{\beta}(1.0)$ leads to a solidification path that is almost identical to the thermodynamic equilibrium binary eutectic reaction valley (BE-TE line), while a very small $g_{\beta}(0.02)$ leads to a solidification path that lies far from the binary eutectic reaction valley. To determine the appropriate value for $g_{\beta}$, a series of simulations with varying $g_{\beta}$ are performed, and the calculated macrosegregation profiles are validated against experimental results, as shown in Figure 10. When $g_{\beta}$ is very small (0.02), positive macrosegregation of Fe $\left(c_{\text {mix }, \mathrm{Fe}}^{\text {index }}\right)$ is mostly concentrated at the sample centre. This is different from the experimental results, which shows two positive segregation peaks at approximately $1 \mathrm{~mm}$ from the sample centre. This simulation-experiment disagreement is attributable to an underestimation of the growth rate of $\beta-\mathrm{Al}_{5} \mathrm{FeSi}$ (or $g_{\beta}$ is too small). Thus, the Fe-enriched melt is transported to the central part before the formation of $\beta-\mathrm{Al}_{5} \mathrm{FeSi}$. When $g_{\beta}$ is too large (1.0), the growth rate of $\beta-\mathrm{Al}_{5} \mathrm{FeSi}$ is overestimated. The formation of $\beta-\mathrm{Al}_{5} \mathrm{FeSi}$ occurs as soon as the thermodynamic condition for $\beta-\mathrm{Al}_{5} \mathrm{FeSi}$ is favourable. The formed $\beta-\mathrm{Al}_{5} \mathrm{FeSi}$ is immediately captured by the columnar phase. The transport of the solute-enriched liquid is effectively blocked by the formed $\beta-\mathrm{Al}_{5} \mathrm{FeSi}$, and there is only a limited amount of Fe that can reach the sample centre, leading to a relatively lower concentration of $\mathrm{Fe}$ (even negative segregation) there. The best simulation-experiment agreement is obtained when $g_{\beta}=0.1$. Therefore, this value is recommended in this study. It should be mentioned that $g_{\beta}$ may depend on alloys and other factors. Further investigations are required to better understand the growth kinetics of $\beta-\mathrm{Al}_{5} \mathrm{FeSi}$ which is outside the scope of the current study.

The melt flow accelerates both the heat and solute transfer near the solidification tip front, and thereby affects the growth kinetics of the dendrite tip. Lee et $a l .^{[29]}$ presented a comprehensive literature review on this topic, while most studies were done in the presence of the thermal convection. A stagnant film model of thermosolutal convection during free dendritic growth of alloys was developed by $\mathrm{Li}$ and Beckermann. ${ }^{[30]}$ The convection effect was considered by introducing the thermal and solutal boundary layer in the transport solutions for the dendrite tip. The boundary layer thicknesses were evaluated through appropriate Nusselt and Sherwood number correlations. However, this model is not valid for the AlSi7Fel alloy where the buoyancy ratio is negative. Note that, in the current study, as the sample is solidified unidirectionally in a Bridgman furnace where the withdrawal velocity of the sample and the temperature gradient are superimposed. The growth velocity of the primary dendrite tips is consistent with the sample withdrawal velocity, and the convection has only effect on the position of the dendrite tips. Based on the current simulation results, the columnar tip front is $\sim 0.9 \mathrm{~mm}$ behind the liquidus isotherm. This distance is about one order of magnitude smaller than the mushy zone thickness $(>10 \mathrm{~mm}$ shown in Figure 8). It indicates that the flow effect on the dendrite growth kinetics, i.e. on the position of the primary dendrite tips, is very limited in the current unidirectional solidification condition.

A wide variety of experiments have been done to investigate the nucleation mechanisms of $\beta-\mathrm{Al}_{5} \mathrm{FeSi}$. Previous investigations suggested that $\beta$-A $1_{5} \mathrm{FeSi}$ prefer to nucleate on small entrained oxide films, ${ }^{[31,32]}$ double oxide films, ${ }^{[33]}$ and aluminium phosphide particles. ${ }^{[34]}$ 


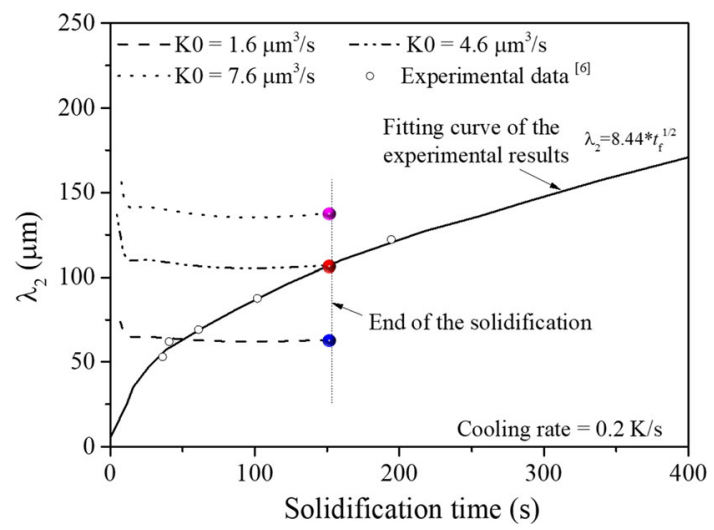

Fig. 11-Numerical parameter study of the effect of $K_{0}$ on $\lambda_{2}$ based on Case V.

Recent experimental studies have focused on the use of in situ methodologies to reveal and quantify nucleation mechanisms of $\beta-\mathrm{Al}_{5} \mathrm{FeSi}$. Terzi et al. ${ }^{[35]}$ found that four $\beta-\mathrm{Al}_{5} \mathrm{FeSi}$ plates nucleated heterogeneously near the surface of the samples, but no nucleation was observed in the interior of the samples. Different from the work done by Terzi et al., ${ }^{[35]}$ Puncreobutr et al. ${ }^{[21]}$ found that the main mechanism of nucleation was on/near aluminum dendrites, occurring in 617 of 959 events, or $\sim 64$ pct of the time, while the surface oxide only played a small role on the nucleation. To be best knowledge of the authors, although different nucleation mechanisms have been proposed, it is still very difficult to quantify their individual effect during the precipitation of intermetallics, especially for the alloy solidified under convection conditions. In the current paper, the nucleation of $\beta-\mathrm{Al}_{5} \mathrm{FeSi}$ was presumed to occur instantaneously when the thermal conditions (phase diagram) are fulfilled.

Based on the in-situ observation, $\beta$ - $\mathrm{Al}_{5} \mathrm{FeSi}$ appeared on or near the well-developed primary aluminium dendrites. $^{[20,21,35]}$ Once nucleated, $\beta$ - $\mathrm{Al}_{5} \mathrm{FeSi}$ plates formed via fast lateral growth $(0.03 \sim 0.1 \mathrm{~mm} / \mathrm{s})$, wrapping around and in between the primary dendrite arms. $^{[20]}$ Nearly 90 pct of the total volume of the $\beta-\mathrm{Al}_{5} \mathrm{FeSi}$ forms via a eutectic reaction $\left(L \rightarrow \alpha-\mathrm{Al}+\beta-\mathrm{Al}_{5} \mathrm{FeSi}\right)^{[19,21]}$ For AlSi7Fe1, $\lambda_{2}$ varies from 50 to $100 \mu \mathrm{m}$. ${ }^{[9]}$ The formed $\beta-\mathrm{Al}_{5} \mathrm{FeSi}$ is generally close to or even larger than the secondary dendrite spacing. ${ }^{[4,20,21,25]}$ All those works imply that the migration of $\beta-\mathrm{Al}_{5} \mathrm{FeSi}$ in the mush is unlikely to occur, and $\beta-\mathrm{Al}_{5} \mathrm{FeSi}$ was usually considered to be fixed with the primary dendrites. ${ }^{[10]}$ Therefore, the migration of $\beta-\mathrm{Al}_{5} \mathrm{FeSi}$, which may be another mechanism for macrosegregation (transporting element $\mathrm{Fe}$ with the $\beta-\mathrm{Al}_{5} \mathrm{FeSi}$ ), can be ignored. Furthermore, ignoring the migration of the precipitates, the current simulation results can reproduce the experimentally obtained segregation profile of $\mathrm{Fe}, e . g$., the two positive segregation peaks of $c_{\text {mix }}^{\text {index }}$ approximately $1 \mathrm{~mm}$ from the centre (Figure 6(b)). This simulation-experiment agreement reveals that the formation and distribution of $\beta-\mathrm{Al}_{5} \mathrm{FeSi}$ are due to the interdendritic flow which transports the
Fe-enriched melt, rather than the migration of $\beta$ - $\mathrm{Al}_{5} \mathrm{FeSi}$.

Although studies on the precipitation/formation of $\beta$ - $\mathrm{Al}_{5} \mathrm{FeSi}$ are plentiful, studies on the blocking effect of $\beta-\mathrm{Al}_{5} \mathrm{FeSi}$ on the interdendritic flow are scarce. To the best of our knowledge, Eqs. [11] and [12] $]^{[10]}$ are the only equations available to quantify the blocking effect on the fluid flow. These equations were directly implemented in the current model and indirectly validated by the model through a comparison of the calculated and experimentally determined macrosegregation. The good simulation-experiment agreement indicates that Eqs. [11] and [12] are valid. Note that in Eqs. [11] and [12], two blocking effect constants $\left(\beta_{\mathrm{P}}, \beta_{\mathrm{N}}\right)$ were used, which were experimentally obtained based on the $\mathrm{Al}-7.52 \mathrm{Si}-3.53 \mathrm{Cu}-0.59 \mathrm{Fe}$ alloy. This alloy is similar, but not identical to the alloy of the current study. The valid scope of Eqs. [11] and [12], including $\beta_{\mathrm{P}}, \beta_{\mathrm{N}}$, is not clear. Therefore, the study of Puncreobutr et al. ${ }^{[10]}$ is necessarily extended to a broader range of alloys and solidification conditions.

Dendrite coarsening is considered by Eq. [15]. As shown by the blue lines in Figure 4(b), under diffusive crystal growth conditions, good agreement between the experimental results ${ }^{[6]}$ and the simulation results is obtained. To investigate the mechanism of solidification under the influence of an RMF, a series of simulations with various cooling rates were carried out for Case V. However, the dendrite coarsening parameters developed for the diffusive crystal growth condition are not valid in Case V, in which the AlSi7 binary alloy is solidified under the RMF. According to the work of Steinbach et al., ${ }^{[2,6]}$ the ripening exponent (b) should increase from $1 / 3$ to $1 / 2$. Neumann-Heyme et al. ${ }^{[12]}$ indicated that $K_{0}$ in Eq. [15] is dependent on the flow condition, cooling rate, and alloy composition. A numerical parameter study was performed by varying $K_{0}$ between $1.0 \mu \mathrm{m}^{3} / \mathrm{s}$ and $30.0 \mu \mathrm{m}^{3} / \mathrm{s}$ and the results are shown in Figure 11. If a small value $\left(e . g ., 1.6 \mu \mathrm{m}^{3} / \mathrm{s}\right)$ is used for $K_{0}$, the calculated as-solidified $\lambda_{2}$ falls below the experimental curve. Similarly, if the value of $K_{0}$ is too large (e.g., 7.6 $\mu \mathrm{m}^{3} / \mathrm{s}$ ), the calculated as-solidified $\lambda_{2}$ also deviates from the experiment curve. The best simulation-experiment agreement is obtained when the value of $K_{0}$ is $4.6 \mu \mathrm{m}^{3} / \mathrm{s}$. It is noteworthy that when the value of $K_{0}$ is $4.6 \mu \mathrm{m}^{3} / \mathrm{s}$, all calculated values of $\lambda_{2}$ under different cooling conditions fall on the experiment curve (Figure 4(b)). Therefore, a value of $4.6 \mu \mathrm{m}^{3} / \mathrm{s}$ for $K_{0}$ is recommended for the current RMF condition. From Figure 4(b), with an extremely low cooling rate $(<0.1 \mathrm{~K} / \mathrm{s})$, a local minimum of $\lambda_{2}$ is observed at a very early stage of the solidification. This might not be expected. The evolution of the secondary dendrites in the undercooled melt near the solidification front is an ongoing topic. A perturbation of the local temperature or solute concentration can initialise the secondary arms. ${ }^{[7]}$ It seems that this local minimum of $\lambda_{2}$ is not fully valid at this very early stage of the solidification. For the subsequent stages of the solidification, Eq. [15] has been verified by experimental results. ${ }^{[6,12]}$ 


\section{CONCLUSIONS}

A novel three-phase volume-average-based solidification model is introduced to simulate the unidirectional solidification of an AlSi7Fel alloy under RMF (6 mT, $50 \mathrm{~Hz}$ ). The modelling results of the $\mathrm{Si}$ and $\mathrm{Fe}$ distribution across the sample section were validated against reported laboratory experiments, and good simulation-experiment agreement is obtained. Knowledge on the dynamic precipitation of $\beta-\mathrm{Al}_{5} \mathrm{FeSi}$ and its effect on solidification and the flow are improved.

(1) The solidification of the AlSi7Fel alloy starts with the development of primary aluminium dendrites $(\alpha-\mathrm{Al})$, followed by the precipitation of $\beta-\mathrm{Al}_{5} \mathrm{FeSi}$ during the binary eutectic reaction. The primary aluminium dendrites of $\alpha$-Al and $\beta-\mathrm{Al}_{5} \mathrm{FeSi}$ precipitates are considered as two different solid phases, and their formations follow different growth kinetics. Herein, a simple formulation for the growth of $\beta-\mathrm{Al}_{5} \mathrm{FeSi}$ is proposed. Despite its simplicity, the solidification path (microsegregation) of this ternary alloy and formed macrosegregation under the influence of an RMF have been demonstrated to be successfully 'reproduced' by the proposed model.

(2) During directional solidification of AlSi7Fel under the stirring of RMF, an azimuthal flow and superimposed meridional flow (Ekman effect) are generated at the solidification front. The forced flow decreases the thickness of the mushy zone, modifies the morphology of the mushy zone, and causes the formation of the central segregation channel with sidearms. In the mushy zone, $c_{\ell, \mathrm{Si}}$ and $c_{\ell, \mathrm{Fe}}$ start with an increase near the solidification front due to solute rejection during the formation of primary aluminium dendrites until the binary eutectic reaction occurs. Since the subsequent formation of $\beta-\mathrm{Al}_{5} \mathrm{FeSi}$ during the binary eutectic reaction consumes a large amount of $\mathrm{Fe}, c_{\ell \mathrm{Fe}}$ gradually decreases. The consumption of $\mathrm{Si}$ in the formation of $\beta-\mathrm{Al}_{5} \mathrm{FeSi}$ is very limited, and hence $c_{\ell, \mathrm{Si}}$ increases consistently.

(3) The macrosegregation profiles of $\mathrm{Si}$ and $\mathrm{Fe}$ across the RMF-stirred sample section are very different: $\mathrm{Si}$ is mostly concentrated at the sample centre, while $\mathrm{Fe}$ shows two segregation peaks at approximately $1 \mathrm{~mm}$ from the centre. This is due to the maximal amount of $\beta-\mathrm{Al}_{5} \mathrm{FeSi}$ formed at approximately $1 \mathrm{~mm}$ from the centre. The formed $\beta-\mathrm{Al}_{5} \mathrm{FeSi}$ is captured by the columnar dendrites where $\mathrm{Fe}$ is 'frozen'. Migration of $\beta-\mathrm{Al}_{5} \mathrm{FeSi}$ in the mushy zone is likely negligible.

(4) In a technical alloy like AlSi7Fe1, the formed $\beta-\mathrm{Al}_{5} \mathrm{FeSi}$ significantly blocks the interdendritic flow under the influence of an RMF. Hence, dendrites appear to follow the coarsening law $\left(\lambda_{2} \propto t_{\mathrm{f}}^{1 / 3}\right)$ of solidification under pure diffusive conditions. This conclusion supports the work of Steinbach et al. ${ }^{[6,9]}$

(5) The dendrite coarsening law of Neumann-Heyme et $a l .{ }^{[12]}$ is incorporated in the model to consider the dynamic evolution of $\lambda_{2}$ and its effect on the interdendritic flow (varying permeability ${ }^{[10]}$ ). Compared with previous models where a constant $\lambda_{2}$ (as-solidified value) is used for the permeability, the current model can improve the simulation accuracy by 8 pct, demonstrated by the results for the Si macrosegregation index.

\section{ACKNOWLEDGMENTS}

The authors acknowledge the financial support from Austrian Research Promotion Agency (FFG) -Austrian Space Application Program (ASAP) through the project FLOWSICONS (No. 859777), Austria Science Fund (FWF, I4278-N36), as well as the support from European Space Agency (ESA) through the project MICAST.

\section{FUNDING}

Open access funding provided by Montanuniversität Leoben.

Open Access This article is licensed under a Creative Commons Attribution 4.0 International License, which permits use, sharing, adaptation, distribution and reproduction in any medium or format, as long as you give appropriate credit to the original author(s) and the source, provide a link to the Creative Commons licence, and indicate if changes were made. The images or other third party material in this article are included in the article's Creative Commons licence, unless indicated otherwise in a credit line to the material. If material is not included in the article's Creative Commons licence and your intended use is not permitted by statutory regulation or exceeds the permitted use, you will need to obtain permission directly from the copyright holder. To view a copy of this licence, visit http://creativecommons. org/licenses/by $/ 4.0 /$.

\section{REFERENCES}

1. M.C. Flemings: ISIJ Int., 2000, vol. 40, pp. 833-41.

2. S. Steinbach and L. Ratke: Mater. Sci. Eng. A, 2005, vols. 413-414, pp. 200-04.

3. T. Campanella, C. Charbon, and M. Rappaz: Metall. Mater. Trans. A Phys. Metall. Mater. Sci., 2004, vol. 35A, pp. 3201-10.

4. P. Mikolajczak and L. Ratke: Metall. Mater. Trans. A Phys. Metall. Mater. Sci., 2015, vol. 46, pp. 1312-27.

5. H. Zhang, M. Wu, Y. Zheng, A. Ludwig, and A. Kharicha: Mater. Today Commun., 2020, vol. 22, p. 100842.

6. S. Steinbach, L. Ratke, G. Zimmermann, L. Sturz, A. Roósz, J. Kovács, Y. Fautrelle, O. Budenkova, L. J., S. Dost, G. G.-U, N. Warnken, M. Wu, and W.H. Sillekens: Proceedings of the 5 th Decennial International Conference on Solidification Processing, Old Windsor, 2017, pp. 267-71.

7. W. Kurz and D.J. Fisher: in Metallography and Microstructures, second., Trans Tech Publications Ltd, Zuerich, 2018, pp. 71-92.

8. D.H. Kirkwood: Mater. Sci. Eng., 1985, vol. 73, pp. L1-L4.

9. S. Steinbach and L. Ratke: Int. J. Cast Met. Res., 2009, vol. 22, pp. 290-93. 
10. C. Puncreobutr, A.B. Phillion, J.L. Fife, and P.D. Lee: Acta Mater., 2014, vol. 64, pp. 316-25.

11. J.C. Ramirez and C. Beckermann: Metall. Mater. Trans. A Phys. Metall. Mater. Sci., 2003, vol. 34A, pp. 1525-36.

12. H. Neumann-Heyme, K. Eckert, and C. Beckermann: Acta Mater., 2017, vol. 140, pp. 87-96.

13. Q. Li and C. Beckermann: Phys. Rev. E Stat. Phys. Plasmas Fluids Relat. Interdiscip. Top., 1998, vol. 57, pp. 3176-88.

14. Y. Zheng, M. Wu, E. Karimi-Sibaki, A. Kharicha, and A. Ludwig: Int. J. Heat Mass Transf., 2018, vol. 122, pp. 939-53.

15. M. Wu, A. Ludwig, and A. Kharicha: Metals, 2019, vol. 9, p. 229.

16. O. Budenkova, F. Baltaretu, S. Steinbach, L. Ratke, A. Roósz, A. Rónaföldi, J. Kovács, A.M. Bianchi, and Y. Fautrelle: Mater. Sci. Forum, 2014, vols. 790-791, pp. 46-51.

17. M. Wu and A. Ludwig: Metall. Mater. Trans. A Phys. Metall. Mater. Sci., 2007, vol. 38A, pp. 1465-75.

18. J. Lipton, M.E. Glicksman, and W. Kurz: Mater. Sci. Eng., 1984, vol. 65 , pp. 57-63.

19. G. Sha, K.A.Q. O'Reilly, B. Cantor, J.M. Titchmarsh, and R.G. Hamerton: Acta Mater., 2003, vol. 51, pp. 1883-97.

20. J. Wang, P.D. Lee, R.W. Hamilton, M. Li, and J. Allison: Scr. Mater., 2009, vol. 60, pp. 516-19.

21. C. Puncreobutr, A.B. Phillion, J.L. Fife, P. Rockett, A.P. Horsfield, and P.D. Lee: Acta Mater., 2014, vol. 79, pp. 292-303.

22. D. Ferdian, B. Suharno, B. Duployer, C. Tenailleau, L. Salvo, and J. Lacaze: Trans. Indian Inst. Met., 2012, vol. 65, pp. 821-25.

23. A. Ludwig and M. Wu: Metall. Mater. Trans. A Phys. Metall. Mater. Sci., 2002, vol. 33, pp. 3673-83.
24. M.C. Schneider and C. Beckermann: Int. J. Heat Mass Transf., 1995, vol. 38, pp. 3455-73.

25. P. Mikolajczak and L. Ratke: Int. J. Cast Met. Res., 2013, vol. 26, pp. 339-53.

26. J.K. Roplekar and J.A. Dantzig: Int. J. Cast Met. Res., 2001, vol. 14, pp. 79-95.

27. A. Rónaföldi, J. Kovács, and A. Roósz: Trans. Indian Inst. Met., 2009, vol. 62, pp. 475-77.

28. O. Budenkova, F. Baltaretu, J. Kovács, A. Roósz, A. Rónaföldi, A.M. Bianchi, and Y. Fautrelle: IOP Conference Series: Materials Science and Engineering, 2012, pp. 012046.

29. Y.W. Lee, R.N. Smith, M.E. Glicksman, and M.B. Koss: Annu. Rev. Heat Transf., 1996, vol. 7, pp. 59-139.

30. Q. Li and C. Beckermann: J. Cryst. Growth, 2002, vol. 236, pp. 482-98.

31. D.N. Miller, L. Lu, and A.K. Dahle: Metall. Mater. Trans. B Process Metall. Mater. Process. Sci., 2006, vol. 37, pp. 873-78.

32. G. Sigworth, J. Campbell, and J. Jorstad: Int. J. Met., 2009, vol. 3, pp. $65-78$.

33. X. Cao and J. Campbell: Metall. Mater. Trans. A Phys. Metall. Mater. Sci., 2003, vol. 34, pp. 1409-20.

34. Y.H. Cho, H.C. Lee, K.H. Oh, and A.K. Dahle: Metall. Mater. Trans. A Phys. Metall. Mater. Sci., 2008, vol. 39, pp. 2435-48.

35. S. Terzi, J.A. Taylor, Y.H. Cho, L. Salvo, M. Suéry, E. Boller, and A.K. Dahle: Acta Mater., 2010, vol. 58, pp. 5370-80.

Publisher's Note Springer Nature remains neutral with regard to jurisdictional claims in published maps and institutional affiliations. 